\title{
Input/Output EMI Filter Design for Three-Phase Ultra-High Speed Motor Drive GaN Inverter Stage
}

\author{
Michael ANTIVACHIS, Pascal Samuel NIKLAUS, Dominik BORTIS, and Johann Walter KOLAR
}

\begin{abstract}
Pairing wide-bandgap (WBG) inverters with highspeed motors results in compact and efficient motor drives, but requires special attention on electromagnetic interference (EMI) aspects. This paper focuses on electromagnetic compatibility (EMC) of high-speed motor drives, supplied by a DC source. In order to protect the nearby equipment from the EMI noise of the WBG inverter, a filter that complies with conducted EMI regulations is placed at the inverter DC input-side. However, there is no clear mandate requiring from inverters to comply with conducted EMI regulations at the AC output-side, where only the motor is placed. For this reason, there is no full consensus whether it is necessary to use an output filter, and if so, what type of output filter would be suitable, i.e., if differential-mode (DM), common-mode (CM) or both $\mathrm{DM} / \mathrm{CM}$ output filter would fit best. A full sine-wave output filter (FSF) is proposed in this paper, that features both DM and CM attenuation, and capacitors connected to the DC link. Besides the several well established benefits of a FSF, such as purely sinusoidal motor currents and the protection of the motor against high $\mathrm{d} u / \mathrm{d} t$ originating from the fast switching of the semiconductor devices, a FSF at the inverter output-side, also reduces the CM EMI emissions at the inverter input-side. Namely, since the inverter housing, the motor housing and the interconnecting shielded cable are all grounded, CM emissions generated at the inverter output-side are directly mapped to the inverter input-side, i.e., there is an input-to-output CM noise interrelation. A FSF reduces the output-side CM EMI emissions and thus mitigates the input-to-output $\mathrm{CM}$ noise mutual influence. Two types of FSF (c-FSF and d-FSF) are comparatively evaluated, in terms of volume, losses and EMI performance. The theoretical consideration are tested within the context of a high-speed 280 krpm, 1 kW motor drive, with $80 \mathrm{~V}$ DC supply. The experimental results validate the good performance of the proposed filter concept.
\end{abstract}

Index Terms-DC source, Electromagnetic compatibility, EMI filter, high-speed, motor drive.

\section{NomenClature}

\begin{abstract}
$u_{\overline{\mathrm{a} o}, \mathrm{DM} \mid \text { fm }}$ Switch-node $\bar{a}$ low-frequency DM voltage component (fundamental motor operation).

$u_{\overline{\mathrm{ao}}, \mathrm{DM} \mid f \mathrm{~s}} \quad$ Switch-node $\bar{a}$ high-frequency DM voltage component (output DM EMI noise source).
\end{abstract}

Manuscript received May 26, 2020; revised August 7, 2020; accepted September 1, 2020. Date of publication March 30, 2021; date of current version March 3, 2021.

All authors are with the Power Electronic Systems Laboratory, ETH Zurich, Zurich 8092, Switzerland (e-mail: antivachis@lem.ee.ethz.ch)

Digital Object Identifier 10.24295/CPSSTPEA.2021.00007 $u_{\overline{\mathrm{io}}, \mathrm{CM} \mid \text { fm }} \quad$ Switch-node $\bar{i} \in\{\bar{a}, \bar{b}, \bar{c}\}$ low-frequency CM voltage component (third harmonic injection).

$u_{\overline{\mathrm{io}}, \mathrm{CM} \mid f \mathrm{~s}} \quad$ Switch-node $\bar{i} \in\{\bar{a}, \bar{b}, \bar{c}\}$ high-frequency CM voltage component (output CM EMI noise source).

$u_{\text {ao, DM } \mid f \mathrm{~s}} \quad$ Inverter output terminal $a$ high-frequency DM voltage.

$u_{\mathrm{io}, \mathrm{CM} \mid f \mathrm{~s}} \quad$ Inverter output terminal $\bar{i} \in\{\bar{a}, \bar{b}, \bar{c}\}$ high-frequency CM voltage.

$u_{\overline{\mathrm{pn}}, \mathrm{DM} \mid f \mathrm{~s}}$ Inverter input DM EMI noise source.

$u_{\overline{\mathrm{pn}}, \mathrm{CM} \mid \mathrm{fs}}$ Inverter input CM EMI noise source.

$u_{\mathrm{pn}, \mathrm{DM} \mid \mathrm{fs}_{\mathrm{s}}}$ Inverter input terminal DM EMI noise.

$u_{\mathrm{pn}, \mathrm{CM} \mid \mathrm{fs}}$ Inverter input terminal CM EMI noise.

$i_{\overline{\mathrm{p}}} \quad$ Inverter DC link switched current.

$I_{\mathrm{p}} \quad$ Inverter input terminal $p$ DC current.

$A_{\mathrm{DM} \mid \mathrm{DMF}} \quad \mathrm{DM}$ attenuation of the output DMF.

$A_{\text {CM|DMF }} \quad \mathrm{CM}$ attenuation of the output DMF.

$A_{\text {DMlc-FSF }} \quad$ DM attenuation of the output c-FSF.

$A_{\mathrm{CM} \text { lc-FsF }} \quad \mathrm{CM}$ attenuation of the output c-FSF.

$A_{\text {DMld-FF }} \quad$ DM attenuation of the output d-FSF.

$A_{\text {CMld-FsF }} \quad$ CM attenuation of the output d-FSF.

$A_{\mathrm{DM}} \quad \mathrm{DM}$ attenuation of the input filter.

$A_{\mathrm{cm}} \quad \mathrm{CM}$ attenuation of the input filter.

\section{INTRODUCTION}

T OW-voltage, high-speed drive systems, supplied by Lan isolated DC network, spread across a wide range of com mercial applications [1], [2]. A $P=1 \mathrm{~kW}, n=280 \mathrm{krpm}$ compressor drive application is considered in this paper, which is visualised in Fig. 1 and summarized in Table. I. The inverter is connected to the high-speed motor through a shielded, four conductor cable (three phases and protective earth (PE)). The isolated DC network $U_{\mathrm{pn}}=80 \mathrm{~V}$, which constitutes the primary energy source of the motor drive, simultaneously supplies sensitive surrounding equipment, which must be protected against EMI emissions originating from the switched inverter. Therefore, an input filter complying with EMC regulations IEC 61800-3 [3] is mandatory.

In contrast to the DC input filter, it is not clear whether a filter should be placed at the inverter $\mathrm{AC}$ output and if so what kind of filter and how strong its attenuation should be. A differential-mode output filter (DMF), as shown in Fig. 2(a), is necessary when a high-speed motor is employed. High-speed motors are sensitive to poor current quality, which causes high rotor losses [4]-[6]. Thus, a DMF which allows for purely sinusoidal motor currents is required. Shifting 


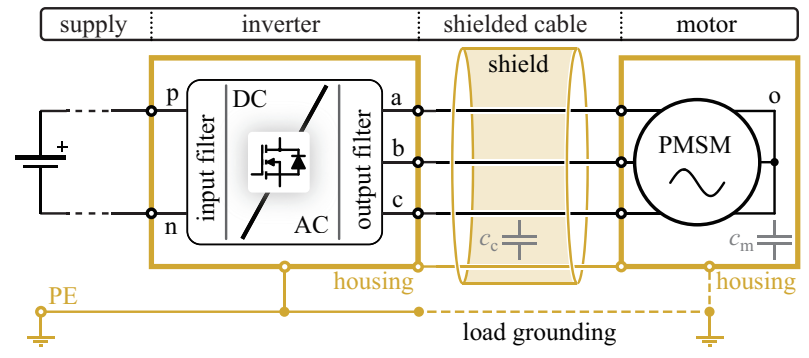

Fig. 1. High-speed motor drive system supplied by an isolated DC source. The motor can be either directly grounded (dashed yellow line applies) or only grounded through the shielded cable (dashed yellow line is neglected).

TABLE I

Specifications of High-Speed Drive System. The Nominal Operating Condition Is Highlighted in Bold.

\begin{tabular}{lc}
\hline \hline Motor speed & $n=0 \mathrm{rpm} \cdots 280 \mathrm{krpm}$ \\
Motor voltage & $\hat{U}_{\mathrm{m}}=0 \cdots 40 \mathrm{~V}$ (Phase, PK) \\
Motor power & $P=0 \cdots 1000 \mathrm{~W}$ \\
Inverter output freq. & $f_{\mathrm{m}}=0 \cdots 5 \mathrm{kHz}$ \\
Inverter input voltage & $U_{\mathrm{pn}}=80 \mathrm{~V}$ \\
Inverter power & $P=0 \cdots 1100 \mathrm{~W}$ \\
\hline \hline
\end{tabular}

towards higher rotational motor speeds $n$ drastically decreases the volume of the motor and the rotating mechanical parts. Thereby, significantly higher motor power density is achieved that outweighs the decrease in inverter performance, due to the additional volume and losses originating from the DMF. In other words, a DMF allows to shift/exchange volume/ losses from the motor towards the inverter, resulting in a better motor drive system performance as a whole. Furthermore, a DMF eliminates overvoltages at the motor terminals and wave reflections problems when long interface cables connect the inverter to the motor [7]-[9].

However, a DMF does not address the problem of commonmode (CM) EMI emissions. The high $\mathrm{d} u / \mathrm{d} t>30 \mathrm{kV} / \mu \mathrm{s}$ that wide-bandgap (WBG) devices exhibit [10]-[12], enables low switching losses, but simultaneously electrically stresses the motor insulation and results in bearing currents [13]-[18]. As a result, high $\mathrm{CM} \mathrm{d} u / \mathrm{d} t$ leads to premature motor failure. In order to guarantee high motor reliability, the inverter output filter must be supplemented by a CM output filter (CMF), which mitigates high $\mathrm{d} u / \mathrm{d} t$. Another advantage of a CMF is described in literature: A CMF not only reduces the $\mathrm{CM}$ emissions at the $\mathrm{AC}$ output-side of the inverter, but also reduces the CM emissions at the DC input-side [19]-[23]. Namely, since the inverter housing, the motor housing and the interconnecting shielded cable are all grounded, CM emissions generated at the inverter output-side are directly mapped to the inverter inputside, i.e., there is an input-to-output CM noise interrelation. A CMF largely prevents CM emissions towards the inverter output and hence resolves the input-to-output $\mathrm{CM}$ noise interrelation problem.
For all the above reasons, a full sine-wave output filter (FSF), which features both DM and CM attenuation is recommended for WBG inverters. Three main categories of FSFs have been proposed in literature:

(i) DC link referenced output filter [24]-[30]. This is a passive output filter, which is capacitively connected/ referenced to the negative/positive DC rails $\bar{p} / \bar{n}$. This type of output filter is analysed in detail within this paper. In particular, two DC link referenced output filter variants, the c-FSF of Fig. 3 and the d-FSF of Fig. 4 are comparatively evaluated.

(ii) Passive CM noise cancellation output filter [31]-[34]. This type of filter offers similar performance to a DC link referenced filter but with additional complexity, hence it is not further considered in this work.

(iii) Active CM noise cancellation output filter [35], [36]. This type of filter effectively reduces CM EMI emissions, by actively switching additional semiconductor devices. Thereby, significant switching losses are generated that compromise the inverter efficiency. For this reason, this output filter type is avoided.

First, the EMI emissions of the inverter, employing a FSF, are theoretically analysed in Section II. Two FSF variants (c-FSF and d-FSF), are comparatively evaluated in terms of volume, losses and EMI performance. A compre-hensive design algorithm for the input and output filter is given in Section III. The experimental verification follows in Section $\mathrm{IV}$, within the context of a $1 \mathrm{~kW}, 280 \mathrm{krpm}$, high-speed motor drive (cf., Table I). The results verify the good performance of the proposed filter concept. Finally, conclusions are drawn in Section V.

\section{TheORETICAL ANALYSIS}

The considered two-level voltage source inverter employs a third harmonic injection modulation (THM) [37], in order to optimally utilize the DC link voltage. The duty cycles controlling the three phases are

$$
\left\{\begin{array}{l}
d_{\mathrm{a}}(t)=M \sin \left(\omega_{\mathrm{m}} t\right)-\frac{1}{6} \sin \left(3 \omega_{\mathrm{m}} t\right) \\
d_{\mathrm{b}}(t)=M \sin \left(\omega_{\mathrm{m}} t-\frac{2 \pi}{3}\right)-\frac{1}{6} \sin \left(3 \omega_{\mathrm{m}} t\right), \\
d_{\mathrm{c}}(t)=M \sin \left(\omega_{\mathrm{m}} t+\frac{2 \pi}{3}\right)-\frac{1}{6} \sin \left(3 \omega_{\mathrm{m}} t\right)
\end{array}\right.
$$

where $M$ is the modulation index

$$
M=\frac{\hat{U}_{\mathrm{m}}}{\frac{1}{2} U_{\mathrm{pn}}}=0 \ldots \frac{2}{\sqrt{3}},
$$

and $\omega_{\mathrm{m}}=2 \pi f_{\mathrm{m}}$ is the motor angular velocity.

In order to facilitate the EMI analysis, the inverter switch node $\bar{a} \bar{b}$ and $\bar{c}$ voltages are simplified into equivalent voltage sources [38] as illustrated in Fig. 5. The switch-node $\bar{a}$ voltage is analytically expressed as 


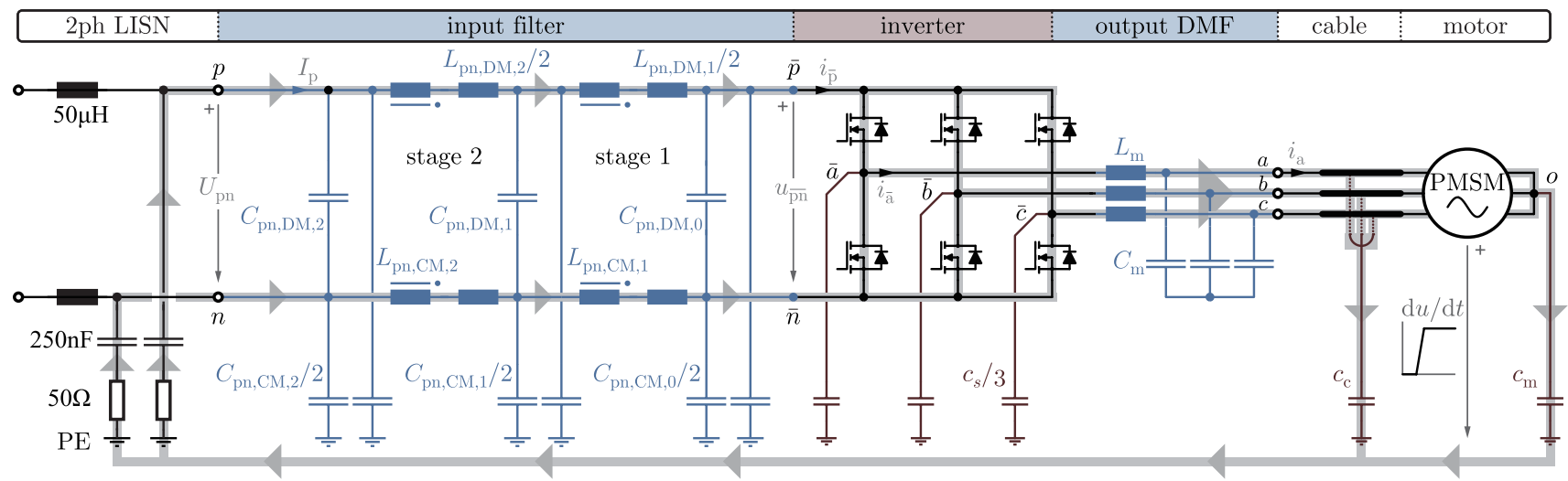

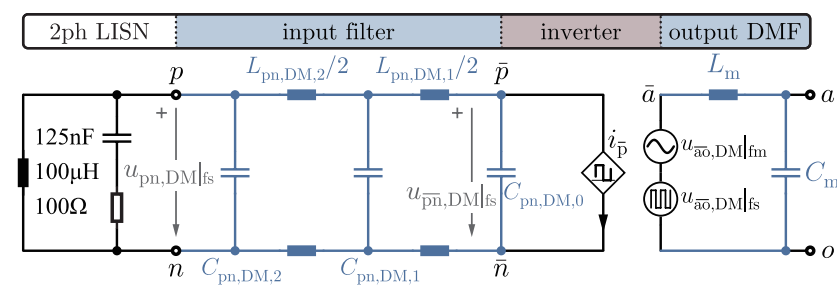

(b)

(a)

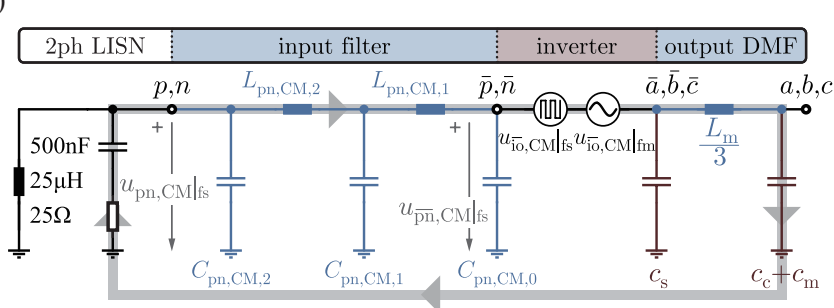

(c)

Fig. 2. (a) Inverter featuring a simple DM output filter (DMF) and a two-stage input filter, (b) DM and (c) CM equivalent circuits.

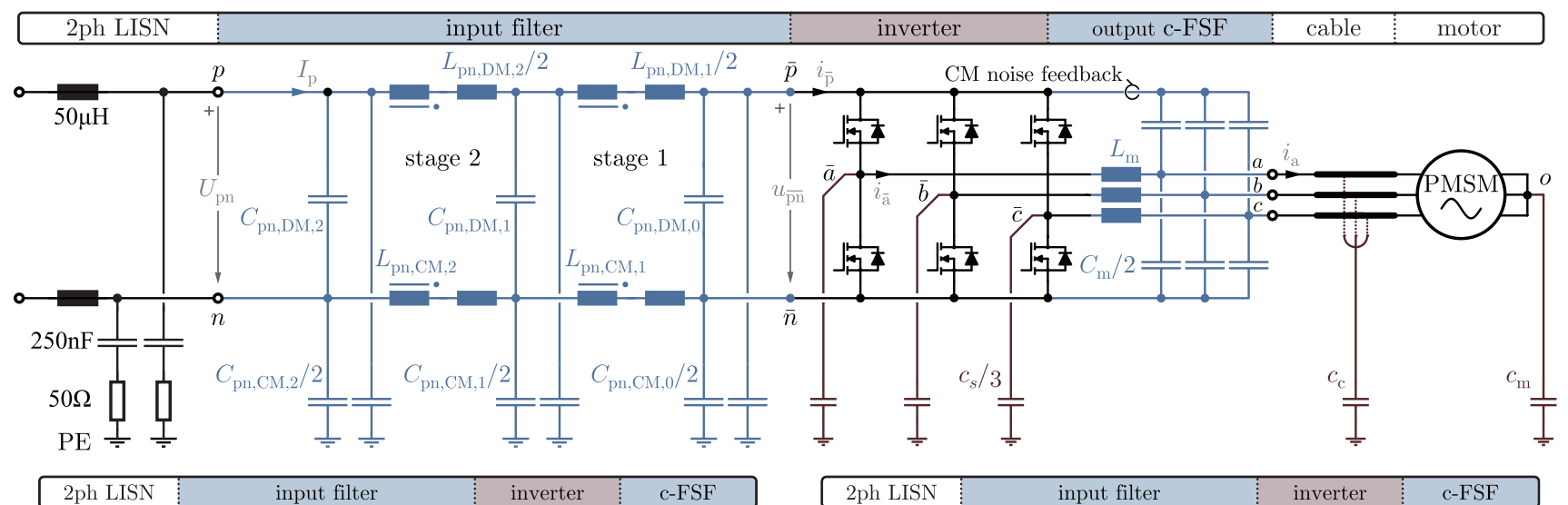

(a)

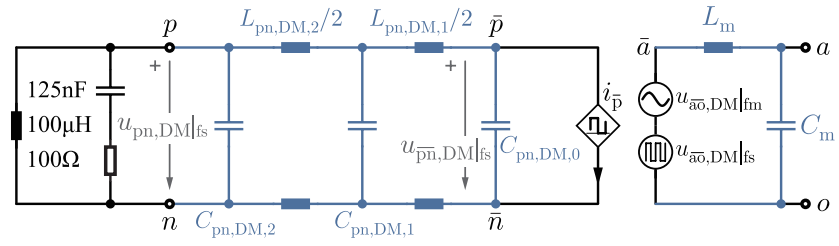

(b)

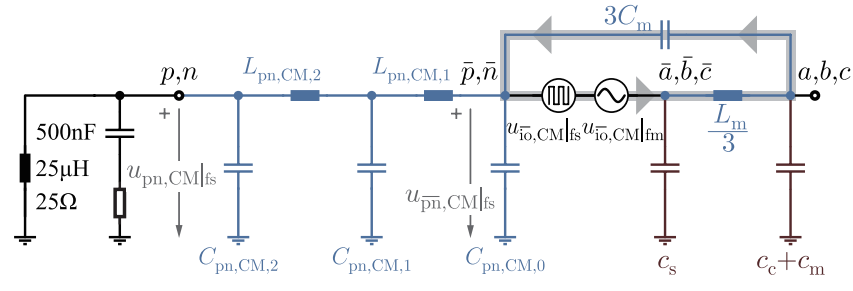

(c)

Fig. 3. (a) Inverter featuring a combined full sine-wave output filter (c-FSF), (b) DM and (c) CM equivalent circuits.

$$
u_{\mathrm{a}-}^{-}(t)=\underbrace{u_{\overline{\mathrm{a}} \mathrm{DM} \mid \mathrm{fm}}+u_{\overline{\mathrm{a}}, \mathrm{DM} \mid \mathrm{s}}}_{u_{\mathrm{ao}, \mathrm{CM}}}+\underbrace{u_{\overline{\mathrm{i}}, \mathrm{CM} / \mathrm{m}}+u_{\overline{\mathrm{io}}, \mathrm{CM} \mid \mathrm{s}}}_{u_{\mathrm{io}, \mathrm{CM}}} .
$$

From now on, the analysis focuses on phase a, however can be easily extended to the remaining two phases. In particular, the voltage component $u_{\text {ao,DM } \mid \text { fm }}$ of (3) is the fundamental frequency
DM voltage, which generates the useful fundamental motor current/torque and depends on the modulation index

$$
u_{\overline{\mathrm{a} o}, \mathrm{DM} \mid f \mathrm{~m}}(t)=M \frac{U_{\mathrm{pn}}}{2} \sin \left(\omega_{\mathrm{m}} t\right) .
$$

The switch-node voltage components $u_{\overline{\mathrm{io}}, \mathrm{CM} \mid \text { fm }}$ is the low- 


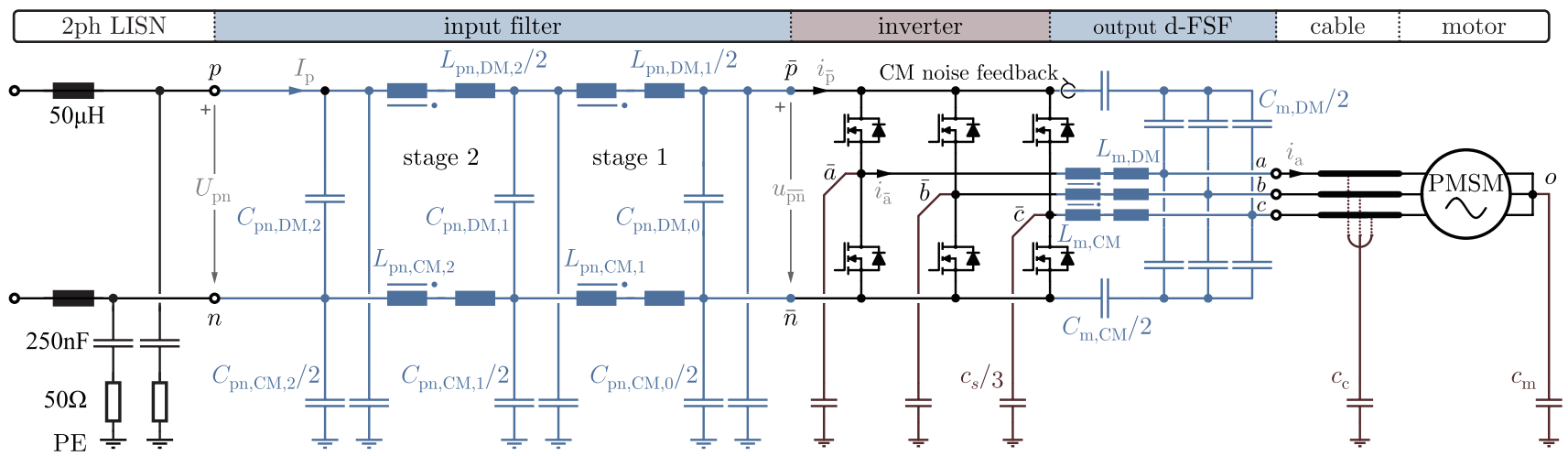

(a)

\begin{tabular}{|l|l|l|l|}
\hline 2ph LISN & input filter & inverter & d-FSF \\
\hline
\end{tabular}

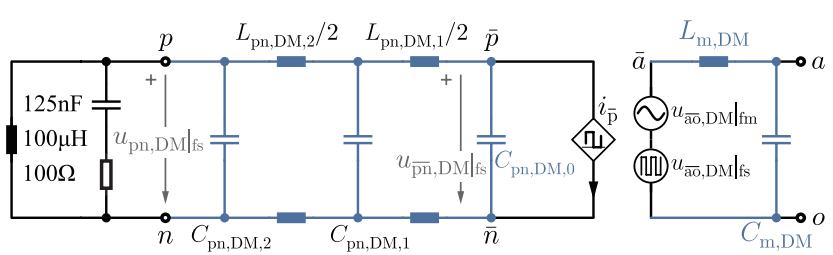

(b)

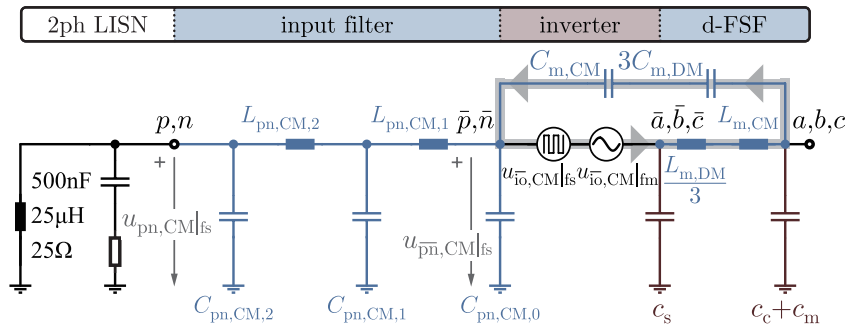

(c)

Fig. 4. (a) Inverter featuring a discrete full sine-wave output filter (d-FSF). (b) DM and (c) CM equivalent circuits.

frequency CM voltage and is the by-product of the employed THM modulation strategy

$$
u_{\overline{\mathrm{io}}, \mathrm{CM} \mid \mathrm{fm}}(t)=-\frac{U_{\mathrm{pn}}}{12} \sin \left(3 \omega_{\mathrm{m}} t\right) .
$$

Finally, the $u_{\overline{\mathrm{ao}}, \mathrm{DM} \mid f \mathrm{~s}}$ and $u_{\overline{\mathrm{io}}, \mathrm{CM} \mid f \mathrm{~s}}$ are the DM and CM highfrequency switch-node voltage components, respectively. Those voltage components are directly related to the PWM switching frequency $f_{\mathrm{s}}$ and are the cause behind EMI emissions. There is no closed form expression for the high-frequency switch-node voltage components $u_{\mathrm{ao}, \mathrm{DM} \mid \text { fs }}(t)$ and $u_{\overline{\mathrm{io}}, \mathrm{CM} \mid \text { s }}(t)$ due to the complicated nature of the respective PWM waveforms. It is more convenient to analyse these voltage components in frequency domain. An upper bound of the high-frequency switch-node voltage components' spectrum is

$$
\left\lceil\hat{U}_{\mathrm{ao}, \mathrm{DM} \mid \mathrm{s} \mathrm{s}}\right\rceil\left(n f_{s}\right)=\left\lceil\hat{U}_{\mathrm{io}, \mathrm{CM} \mid \mathrm{s} \mathrm{s}}\right\rceil\left(n f_{s}\right)=\frac{2 U_{\mathrm{pn}}}{n \pi},
$$

where $n=1,3,5 \ldots$ is the harmonic order corresponding to the harmonic frequency $f=n f_{s}$. This spectrum is calculated by assuming a rectangular voltage waveform, with an amplitude $U_{\text {pn }} / 2$, a $50 \%$ duty cycle and a repetition frequency equal to the switching frequency $f_{\mathrm{s}}$. It is noted that the switch-node CM voltage components $u_{\overline{\mathrm{io}}, \mathrm{CM} \mid f \mathrm{~m}}$ and $u_{\overline{\mathrm{io}}, \mathrm{CM} \mid \text { fs }}$ are the same for all three phases $\bar{i} \in\{\bar{a}, \bar{b}, \bar{c}\}$.

\section{A. Drawbacks of Different-Mode Output Filter (DMF)}

A simple DM output filter (DMF) is illustrated in Fig. 2(a). There, the semiconductor devices, cable and motor parasitic impedances to protective earth, are represented by the capacitors $c_{\mathrm{s}}, c_{\mathrm{c}}$ and $c_{\mathrm{m}}$, respectively. This capacitive representation is valid for frequencies ranging up to approximately $1 \mathrm{MHz}$ [39]. In general, lower case notation, e.g., $c_{\mathrm{s}}$, is used for parasitic elements. The semiconductor devices' parasitic capacitance $c_{\mathrm{s}}$ is low thanks to the small packaging of the employed $\mathrm{GaN}$ semiconductor devices. In contrast, the cable/motor parasitic capacitances $c_{\mathrm{c}}+c_{\mathrm{m}}$ are significantly larger than $c_{\mathrm{s}}$, due to the large physical dimensions of the cable and the motor housing.

The DMF generates sinusoidal currents for the high-speed motor. By employing the voltage source equivalent inverter model of Fig. 5, and applying the superposition technique, the DM equivalent circuit of the DMF is derived, in Fig. 2(b). The DMF behaves as a second order filter with a DM attenuation

$$
A_{\text {DMIDMF }}(f)=\left|\frac{f_{\mathrm{r}, \mathrm{DM} \mid \mathrm{DMF}}^{2}}{f_{\mathrm{r}, \mathrm{DM} \mid \mathrm{DMF}}^{2}-f^{2}}\right|,
$$

where $f$ is the harmonic frequency and $f_{\mathrm{r}, \mathrm{DM} \mid \mathrm{DMF}}$ is the DM resonant frequency

$$
f_{\mathrm{m}}<f_{\mathrm{r}, \text { DMIDMF }}=\frac{1}{2 \pi \sqrt{L_{\mathrm{m}} C_{\mathrm{m}}}}<f_{\mathrm{s}} .
$$

Only a small residual high-frequency DM voltage $u_{\mathrm{ao}, \mathrm{DM} \mid \mathrm{fs}_{\mathrm{s}}}$ appears at the inverter output terminal a with a spectrum

$$
\hat{U}_{\mathrm{ao}, \mathrm{DM} \mid \mathrm{s}}(f)=\mathrm{A}_{\mathrm{DMIDMF}} \cdot \hat{U}_{\overline{\mathrm{ao}, \mathrm{DM} \mid f \mathrm{~s}}} \cdot
$$




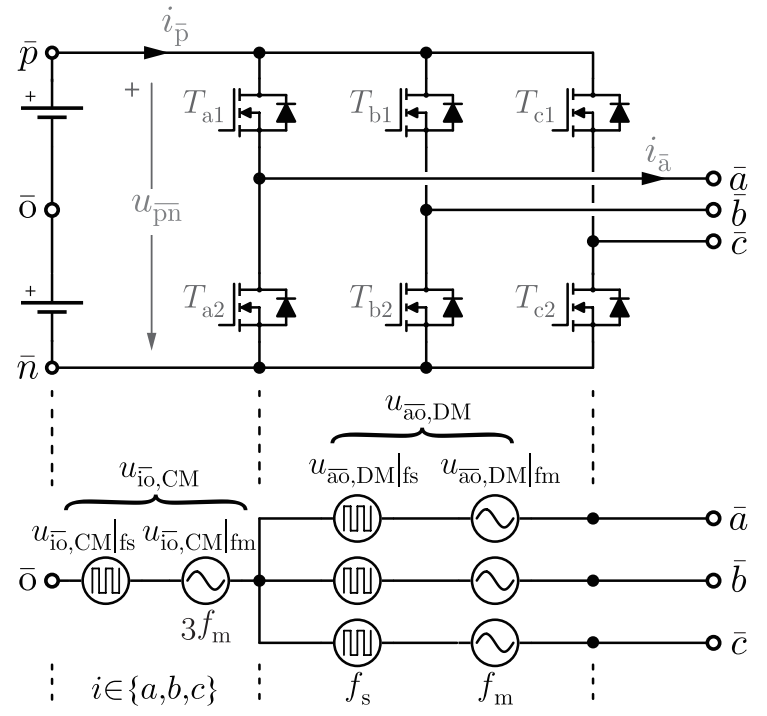

Fig. 5. Equivalent circuit of a two-level voltage source inverter.

However, a DMF does not address the problem of CM EMI emissions. High-frequency CM voltage (and $\mathrm{d} u / \mathrm{d} t$ ) is applied on the motor, which stresses its insulation and causes bearing currents. By employing the voltage source inverter model of Fig. 5, the CM equivalent circuit [20], [40] of the DMF is derived in Fig. 2(c). The cable and motor parasitic capacitances can be lumped into a single capacitance $c_{\mathrm{c}}+c_{\mathrm{m}}$, for the sake of simplicity. The DMF does not attenuate CM voltage, i.e., it features a unity $\mathrm{CM}$ attenuation

$$
A_{\text {CMIDMF }}(f)=1 \text {. }
$$

Even though a second order CM filter is formed by the DMF inductors $L_{\mathrm{m}} / 3$ and the parasitic capacitances $c_{\mathrm{c}}+c_{\mathrm{m}}$, the filtering effect can be neglected, because the cut-off frequency of this filter is in the range of several $\mathrm{MHz}$, due to the small value of the parasitic capacitances $(-100 \mathrm{pF})$. The spectrum of the $\mathrm{CM}$ voltage at the inverter output terminals is

$$
\hat{U}_{\mathrm{io}, \mathrm{CM} / \mathrm{s}}(f)=A_{\mathrm{CMIDMF}} \cdot \hat{U}_{\overline{\mathrm{io}, \mathrm{CM} / \mathrm{s}}}=\hat{U}_{\overline{\mathrm{io}, \mathrm{CM} / \mathrm{s}}} \cdot
$$

Therefore, the switch-node CM voltage $u_{\overline{\mathrm{io}}, \mathrm{CM} \mid \text { fs }}$ (and high $\mathrm{d} u / \mathrm{d} t)$ is directly applied to the cable/motor. This is a major drawback for the DMF.

Furthermore, a DMF results in high EMI emissions at the DC input-side. High $\mathrm{d} u / \mathrm{d} t$ is applied on the cable/motor parasitic capacitances $c_{\mathrm{m}}+c_{\mathrm{c}}$, inducing unwanted CM currents. These parasitic CM currents, form a return path through the DC inputside, thereby causing input CM EMI emissions, as is highlighted in Fig. 2(a). This interdependence between the input-side and output-side CM EMI emissions can be quantified by considering the CM equivalent circuit of Fig. 2(c). There, the equivalent input CM EMI noise source $u_{\overline{\mathrm{pn}}, \mathrm{CM} \mid f \mathrm{~s}}$ must be attenuated by the depicted two-stage input filter, such that the input terminal $\mathrm{p} / \mathrm{n}$ voltage, $u_{\mathrm{pn}, \mathrm{CM} \mid f_{\mathrm{s}}}$ lies within the required EMI limits. The spectrum of the input CM EMI noise source $u_{\overline{\mathrm{pn}}, \mathrm{CM} \mid f \mathrm{~s}}$ is calculated based on the CM equivalent circuit of Fig. 2(c) as

$$
\begin{aligned}
\left\lceil\hat{U}_{\mathrm{pn}, \mathrm{CM} \mid \mathrm{s}}^{-}\right\rceil\left(n f_{\mathrm{s}}\right) & \cong \frac{c_{\mathrm{s}}+c_{\mathrm{c}}+c_{\mathrm{m}}}{C_{\mathrm{pn}, \mathrm{CM}, 0}+c_{\mathrm{s}}+c_{\mathrm{c}}+c_{\mathrm{m}}}\left\lceil\hat{U}_{\overline{\mathrm{i}}, \mathrm{CM} / \mathrm{s}}\right\rceil \\
& =\frac{c_{\mathrm{s}}+c_{\mathrm{c}}+c_{\mathrm{m}}}{C_{\mathrm{pn}, \mathrm{CM}, 0}+c_{\mathrm{s}}+c_{\mathrm{c}}+c_{\mathrm{m}}} \frac{2 U_{\mathrm{pn}}}{n \pi} .
\end{aligned}
$$

The high-frequency switch-node CM voltage $u_{\overline{\mathrm{io}}, \mathrm{CM} \mid \text { fs }}(6)$ is the origin of CM EMI emissions. The input CM EMI emissions $u_{\overline{\mathrm{pn}} \mathrm{CM} \mid \text { \&s }}$ are proportional to the sum of the parasitic capacitances $c_{\mathrm{s}}+c_{\mathrm{c}}+c_{\mathrm{m}}$ (semiconductor devices, cable and motor) and inversely proportional to the input filter DC link CM capacitance $C_{\mathrm{pn}, \mathrm{CM}, 0 .}$. Depending on the length of the cable and/or the motor housing a different total parasitic capacitance $c_{\mathrm{c}}+c_{\mathrm{m}}$ is formed. Consequently, the CM EMI noise at the input-side depends on the mechanical installation of the motor drive at the output-side, i.e., input-to-output CM noise mutual influence. Given the numerous applications of motor drives and the variety of end users, the interdependency of the inputside CM emissions to the output mechanical installation is unwanted. When only a DMF is employed, it is difficult to predict the CM EMI emissions at the DC input-side and it is equally challenging to design an appropriate input filter. For all the above reasons, a pure DMF should be avoided.

\section{B. Combined Full Sine-Wave Output Filter (c-FSF)}

In order to resolve the deficiencies of the simple DMF, a FSF is recommended, that features both DM and CM attenuation. The combined full sine-wave output filter (c-FSF), visualized in Fig. 3(a), is first investigated. The c-FSF employs three individual inductors and visually resembles the DMF of Fig. 2(a). However, in contrast to a DMF, the filter capacitors $C_{\mathrm{m}} / 2$ are directly connected to the positive/negative DC rails $\overline{\mathrm{p}} / \overline{\mathrm{n}}$. Thereby, CM emissions can return through the filter capacitors to the DC link and the semiconductor devices, which created the CM emissions in the first place. The same physical components $C_{\mathrm{m}}, L_{\mathrm{m}}$ are utilized simultaneously for $\mathrm{DM}$ and CM output filter attenuation, justifying the name "combined" full sine-wave filter.

The c-FSF generates sinusoidal currents/voltages for the high-speed motor. By employing the voltage souse inverter model of Fig. 5, the DM equivalent circuit of the c-FSF is derived in Fig. 3(b). The c-FSF is equivalent to a second order filter with DM attenuation

$$
A_{\mathrm{DM} \mid \mathrm{c}-\mathrm{FSF}}(f)=\left|\frac{f_{\mathrm{r}, \mathrm{DM} \mid \mathrm{c}-\mathrm{FSF}}^{2}}{f_{\mathrm{r}, \mathrm{DM} \mid \mathrm{c}-\mathrm{FSF}}^{2}-f^{2}}\right|,
$$

where $f_{\mathrm{r}, \mathrm{DM} \mid \mathrm{lc}-\mathrm{SF}}$ is the DM resonant frequency

$$
f_{\mathrm{m}}<f_{\mathrm{r}, \mathrm{DM} \mid \mathrm{c}-\mathrm{FSF}}=\frac{1}{2 \pi \sqrt{L_{\mathrm{m}} C_{\mathrm{m}}}}<f_{\mathrm{s} .}
$$

The DM resonant frequency $f_{\mathrm{r}, \mathrm{DM} \mid \mathrm{c}-\mathrm{FSF}}$ is selected such that the fundamental voltages/currents are sinusoidal and the high- 
frequency switch-node DM voltage component $u_{\overline{\mathrm{a}}, \mathrm{DM} \mid f_{\mathrm{s}}}$ is effectively attenuated. The resulting DM voltage spectrum at the output terminal a is

$$
\hat{U}_{\mathrm{ao}, \mathrm{DM} \mid \mathrm{s}}(f)=A_{\mathrm{DM} \mid \mathrm{c}-\mathrm{FSF}} \cdot \hat{U}_{\mathrm{a}, \mathrm{DM} \mid \mathrm{s}} \cdot
$$

The c-FSF resolves the CM EMI emissions problem: A FSF eliminates $\mathrm{d} u / \mathrm{d} t$ at the output-side, thus protects the motor bearing and windings from excessive electrical stress. By employing the voltage souse inverter model of Fig. 5, the c-FSF CM equivalent circuit is derived in Fig. 3(c). The CM equivalent circuit is formed by the parallel connection of all three filter inductors $L_{\mathrm{m}} / 3$ and capacitors $3 C_{\mathrm{m}}$. The c-FSF is equivalent to a second order filter with $\mathrm{CM}$ attenuation

$$
A_{\mathrm{CMlc}-\mathrm{FSF}}(f)=\left|\frac{f_{\mathrm{r}, \mathrm{CM} \mid \mathrm{c}-\mathrm{FSF}}^{2}}{f_{\mathrm{r}, \mathrm{CM} \mid \mathrm{c}-\mathrm{FSF}}^{2}-f^{2}}\right|,
$$

where $f_{\mathrm{r}, \mathrm{CM} \mid \mathrm{c}-\mathrm{FSF}}$ is the $\mathrm{CM}$ resonant frequency

$$
f_{\mathrm{m}}<f_{\mathrm{r}, \mathrm{CM} \mid \mathrm{c}-\mathrm{FSF}}=\frac{1}{2 \pi \sqrt{L_{\mathrm{m}} C_{\mathrm{m}}}}<f_{\mathrm{s}} .
$$

Accordingly, the spectrum of the CM voltage (worst case approximation) at the inverter output terminals is

$$
\hat{U}_{\mathrm{io}, \mathrm{CM} \mid \mathrm{s}}(f)=A_{\mathrm{CMlc}-\mathrm{FSF}} \cdot \hat{U}_{\overline{\mathrm{io}}, \mathrm{CM} \mid \mathrm{s}} \cdot
$$

In the case of the c-FSF, the attenuation and resonant frequency of the DM and $\mathrm{CM}$ equivalent circuits are by definition equal, i.e., $A_{\text {DMlc-rsF }}(f)=A_{\text {cMlc-rSF }}(f)$ and $f_{\text {r,Dulc-rsF }}=f_{\text {r,cmlc-rsF }}$.

Furthermore, a FSF achieves low CM EMI emissions at the input: The cable parasitic capacitance $c_{\mathrm{c}}$ and the motor parasitic capacitance $c_{\mathrm{m}}$ do not conduct unwanted CM currents, which would close a loop through the DC input-side, thereby causing CM EMI noise. The CM EMI emissions at the input-side, can be quantified by considering the $\mathrm{CM}$ equivalent circuit of Fig. 3(c). The spectrum of the equivalent input CM EMI noise source $u_{\overline{\mathrm{p}}, \mathrm{CM} \mid f \mathrm{~s}}$ is derived

$$
\begin{aligned}
\left\lceil\hat{U}_{\overline{\mathrm{pn}, \mathrm{CM} \mid \mathrm{s}}}\right\rceil\left(n f_{\mathrm{s}}\right) & \cong \frac{c_{\mathrm{s}}}{C_{\mathrm{pn}, \mathrm{CM}, 0}+c_{\mathrm{s}}}\left\lceil\hat{U}_{\overline{\mathrm{i} o}, \mathrm{CM} / \mathrm{s}}\right\rceil \\
& =\frac{c_{\mathrm{s}}}{C_{\mathrm{pn}, \mathrm{CM}, 0}+c_{\mathrm{s}}} \frac{2 U_{\mathrm{pn}}}{n \pi}
\end{aligned}
$$

The CM EMI emissions at the input are proportional to the parasitic capacitance $c_{\mathrm{s}}$ of the semiconductor devices. The overall input CM EMI emissions, in the case of a c-FSF, are significantly lower compared to the case of a DMF (cf., Fig. 2), where the input CM EMI emissions are proportional to the semiconductor/cable/motor parasitic capacitances $c_{\mathrm{s}}+c_{\mathrm{c}}+c_{\mathrm{m}}$ (12). Thanks to the c-FSF, the input CM emissions do nearly not depend on the mechanical installation at the output side (cable, motor). For all the above reasons, a c-FSF presents several advantages compared to a DMF counterpart, hence, should be preferred.

\section{Discrete Full Sine-Wave Output Filter (d-FSF)}

A second FSF variant is now investigated. This output filter is denoted as discrete full sine-wave output filter (d-FSF) and is shown in Fig. 4(a). The d-FSF employs a three-phase choke $L_{\text {m,CM}}$, in contrast to a c-FSF that employs three individual inductors (cf., Fig. 3(a)). The leakage inductance of the choke windings is used as DM inductance $L_{\mathrm{m}, \mathrm{DM}}$. The d-FSF uses "discrete" dedicated components for the DM attenuation $\left(L_{\mathrm{m}, \mathrm{DM}}\right.$, $\left.C_{\mathrm{m}, \mathrm{DM}}\right)$ and the CM attenuation $\left(L_{\mathrm{m}, \mathrm{CM}}, C_{\mathrm{m}, \mathrm{CM}}\right)$. Thereby, the $\mathrm{DM}$ and $\mathrm{CM}$ output filter parts are decoupled from each other and can be designed independently.

The d-FSF generates sinusoidal motor currents/voltages. The DM equivalent circuit is shown in Fig. 4(b). The d-FSF is equivalent to a second order filter with DM attenuation

$$
A_{\text {DMld-FSF }}(f)=\left|\frac{f_{\mathrm{r}, \mathrm{DMId}-\mathrm{FSF}}^{2}}{f_{\mathrm{r}, \mathrm{DMld}-\mathrm{FSF}}^{2}-f^{2}}\right|,
$$

where $f_{\mathrm{r}, \mathrm{DM} \mid \mathrm{d}-\mathrm{SPF}}$ is the DM resonant frequency

$$
f_{\mathrm{m}}<f_{\mathrm{r}, \mathrm{DMld}-\mathrm{FSF}}=\frac{1}{2 \pi \sqrt{L_{\mathrm{m}, \mathrm{DM}} C_{\mathrm{m}, \mathrm{DM}}}}<f_{\mathrm{s}}
$$

The spectrum of the DM voltage at the inverter output terminal $\mathrm{a}$ is

$$
\hat{U}_{\mathrm{ao}, \mathrm{DM} \mid \mathrm{fs}}(f)=A_{\mathrm{DM} \mid \mathrm{d}-\mathrm{FSF}} \cdot \hat{U}_{\mathrm{ao}, \mathrm{DM} \mid \mathrm{s}} \cdot
$$

The d-FSF resolves the CM EMI emissions problem. The $\mathrm{CM}$ equivalent circuit is shown in Fig. 4(c) and comprises a second order filter with CM attenuation

$$
A_{\mathrm{CM} I \mathrm{~d}-\mathrm{FSF}}(f)=\left|\frac{f_{\mathrm{r}, \mathrm{CM} / \mathrm{d}-\mathrm{FSF}}^{2}}{f_{\mathrm{r}, \mathrm{CM} \mid \mathrm{d}-\mathrm{FSF}}^{2}-f^{2}}\right| .
$$

The CM resonant frequency $f_{\mathrm{r}, \mathrm{CM} / \mathrm{d}-\mathrm{FSF}}$ is

$$
f_{\mathrm{m}}<f_{\mathrm{r}, \mathrm{CM} \mid \mathrm{d}-\mathrm{FSF}}=\frac{1}{2 \pi \sqrt{L_{\mathrm{m}, \mathrm{CM}}^{\prime} C_{\mathrm{m}, \mathrm{CM}}^{\prime}}}<f_{\mathrm{s}},
$$

where $L_{\mathrm{m}, \mathrm{CM}}^{\prime}$ is the equivalent $\mathrm{CM}$ inductance

$$
L_{\mathrm{m}, \mathrm{CM}}^{\prime}=L_{\mathrm{m}, \mathrm{CM}}+\frac{L_{\mathrm{m}, \mathrm{DM}}}{3} \stackrel{L_{\mathrm{m}, \mathrm{CM}}>L_{\mathrm{m}, \mathrm{MM}}}{=} L_{\mathrm{m}, \mathrm{CM},}
$$

and $C_{\mathrm{m}, \mathrm{CM}}^{\prime}$ is the equivalent $\mathrm{CM}$ capacitance

$$
C_{\mathrm{m}, \mathrm{CM}}^{\prime}=\frac{C_{\mathrm{m}, \mathrm{CM}}+3 C_{\mathrm{m}, \mathrm{DM}}}{C_{\mathrm{m}, \mathrm{CM}} \cdot 3 C_{\mathrm{m}, \mathrm{DM}}} \stackrel{C_{\mathrm{m}, \mathrm{MM}} \gg \mathrm{C}_{\mathrm{m}, \mathrm{CM}}}{=} C_{\mathrm{m}, \mathrm{CM} .}
$$

The spectrum of the CM voltage (worst case approximation) at 
the inverter output terminals is

$$
\hat{U}_{\mathrm{io}, \mathrm{CM} \mid \mathrm{s} \mathrm{S}}(f)=A_{\mathrm{CMId}-\mathrm{FSF}} \cdot \hat{U}_{\overline{\mathrm{io}, \mathrm{CM} \mid \mathrm{s}}}
$$

The CM EMI emissions at the input-side, can be quantified by considering the $\mathrm{CM}$ equivalent circuit of Fig. 4(c). The spectrum of the equivalent input CM EMI noise source $u_{\overline{\mathrm{pn}}, \mathrm{CM} \mid f \mathrm{~s}}$ is the same as in the case of a c-FSF (19). This is expected, since both c-FSF and d-FSF largely attenuate CM emissions (and $\mathrm{d} u$ / $\mathrm{d} t$ ) towards the AC output-side.

\section{Input Filter}

An input filter with $N=2$ stages is employed (cf., Fig. 2(a)) in order to ensure that the system complies with the IEC 61800-3 conducted EMI limits at the DC input-side [3]. The DC link comprises the DM capacitor $C_{\mathrm{pn}, \mathrm{DM}, 0}$ and the CM Y2 capacitors $C_{\mathrm{pn}, \mathrm{CM}, 0}$. Each of the subsequent filter stages $k=1$, $\ldots, 2$, is identical and includes a second order DM filter $\left(L_{\mathrm{pn}, \mathrm{DM}, \mathrm{k}}\right.$, $\left.C_{\mathrm{pn}, \mathrm{DM}, \mathrm{k}}\right)$ and a second order CM filter $\left(L_{\mathrm{pn}, \mathrm{CM}, \mathrm{k}}, C_{\mathrm{pn}, \mathrm{CM}, \mathrm{k}}\right)$.

Considering the DM part of the input filter, the input filter attenuates the equivalent input DM noise source $u_{\overline{\mathrm{pn}}, \mathrm{DM} \mid \text { fs }}$, such that the input terminal $\mathrm{p} / \mathrm{n}$ DM voltage $u_{\mathrm{pn}, \mathrm{DM} \mid \mathrm{fs}}$ lies within the required EMI limits. The origin of the DM input EMI noise $u_{\overline{\mathrm{pn}}, \mathrm{DM} \mid / \mathrm{s}}$ is the switched DC link current $i_{\overline{\mathrm{p}}}$ of the inverter, which in return generates voltage ripple across the DC link DM capacitor $C_{\mathrm{pn}, \mathrm{DM}, 0}$. An upper bound of the input-side DM EMI noise source $u_{\overline{\mathrm{pn}}, \mathrm{DM} \mid / \mathrm{s}}$ spectrum is

$$
\left\lceil\hat{U}_{\overline{\mathrm{pn}, \mathrm{DM} \mid \mathrm{s}_{\mathrm{s}}}}\right\rceil\left(n f_{\mathrm{s}}\right)=\frac{1}{n 2 \pi f_{\mathrm{s}} C_{\mathrm{pn}, \mathrm{DM}, 0}} \frac{2 \hat{I}_{\mathrm{m}}}{n \pi} .
$$

The input DM EMI noise source $u_{\overline{\mathrm{p}}, \mathrm{DM} \mid \text { s }}$ is not affected by the output filter type (DMF or FSF) [41]. The DM attenuation of the input filter is

$$
A_{\mathrm{DM}}(f)=\left|\frac{f_{\mathrm{r}, \mathrm{DM}}^{4}}{f_{\mathrm{r}, \mathrm{DM}}^{4}+f^{4}-3 f^{2} f_{\mathrm{r}, \mathrm{DM}}^{2}}\right|,
$$

where $f_{\mathrm{r}, \mathrm{DM}}$ is the DM resonant frequency of each input filter stage

$$
f_{\mathrm{r}, \mathrm{DM}}=\frac{1}{2 \pi \sqrt{L_{\mathrm{pn}, \mathrm{DM}, \mathrm{i}} C_{\mathrm{pn}, \mathrm{DM}, \mathrm{i}}}}<f_{\mathrm{s}} .
$$

The spectrum of the DM EMI noise at the inverter input terminals $\mathrm{p} / \mathrm{n}$ is

$$
\hat{U}_{\mathrm{pn}, \mathrm{DM} \mid \mathrm{s}}(f)=A_{\mathrm{DM}} \cdot \hat{U}_{\overline{\mathrm{pn}, \mathrm{DM} \mid \mathrm{s}}} \cdot
$$

Considering now the CM part of the input filter, the input filter attenuates the equivalent input CM noise source $u_{\overline{\mathrm{pn}}, \mathrm{CM} \mid \mathrm{fs}}$, such that the input terminal $\mathrm{p} / \mathrm{n} \mathrm{CM}$ voltage $u_{\mathrm{pn}, \mathrm{CM} \mid \text { fs }}$ lies within the required EMI limits. The input CM noise source $u_{\overline{\mathrm{pn}}, \mathrm{CM} \mid f \mathrm{~s}}$ depends on the employed output filter type. It is significantly higher in the case of a DMF (12), compared to the case of a FSF (19). The CM attenuation of the input filter is

$$
A_{\mathrm{CM}}(f)=\left|\frac{f_{\mathrm{r}, \mathrm{CM}}^{4}}{f_{\mathrm{r}, \mathrm{CM}}^{4}+f^{4}-3 f^{2} f_{\mathrm{r}, \mathrm{CM}}^{2}}\right|,
$$

where $f_{\mathrm{r}, \mathrm{CM}}$ is the $\mathrm{CM}$ resonant frequency of each input filter stage

$$
f_{\mathrm{r}, \mathrm{CM}}=\frac{1}{2 \pi \sqrt{L_{\mathrm{pn}, \mathrm{CM}, \mathrm{i}} C_{\mathrm{pn}, \mathrm{CM}, \mathrm{i}}}}<f_{\mathrm{s}}
$$

The spectrum of the CM EMI noise at the inverter input terminals $\mathrm{p} / \mathrm{n}$ is

$$
\hat{U}_{\mathrm{pn}, \mathrm{CM} \mid \mathrm{ss}}(f)=A_{\mathrm{CM}} \cdot \hat{U}_{\overline{\mathrm{pn}, \mathrm{CM} \mid \mathrm{s}}}
$$

\section{Design Guidelines}

\section{A. Output Filter}

The output filter should not interfere with the fundamental motor currents/voltages. Based on this objective, the c-FSF is first designed. The DM resonant frequency $f_{\mathrm{r}, \mathrm{Dm} \mid \mathrm{c}-\mathrm{SFF}}$ of a c-FSF (14) should be amply spaced between the fundamental motor frequency $f_{\mathrm{m}}$ and the switching frequency $f_{\mathrm{s}}$

$$
f_{\mathrm{m}} a_{\mathrm{f}} \leqslant f_{\mathrm{r}, \mathrm{DMlc}-\mathrm{FSF}} \leqslant f_{\mathrm{s}} / a_{\mathrm{f}},
$$

where $a_{\mathrm{f}} \geqslant 7$ is an empirical design parameter. A low resonant frequency is related to strong DM filter attenuation and hence good motor voltage quality. However, a very low resonant frequency $f_{\mathrm{r}, \mathrm{DM} \mid \mathrm{C}-\mathrm{FSF}}<f_{\mathrm{m}} a_{\mathrm{f}}$, leads to excessive output filter reactive power. On the other hand, a high DM resonant frequency yields smaller passive component values and accordingly a more compact output filter. A very high DM resonant frequency $f_{\mathrm{r} \text {,Dmlc--SF }}<f_{\mathrm{s}} / a_{\mathrm{f}}$ causes an excitation of the output filter resonance and thus excessively large currents. Based on the resonant frequency constraint of (35), the following inequality must hold for the switching frequency

$$
f_{\mathrm{m}} a_{\mathrm{f}} \leqslant \frac{f_{\mathrm{s}}}{a_{\mathrm{f}}} \rightarrow f_{\mathrm{s}} \geqslant a_{\mathrm{f}}^{2} f_{\mathrm{m}} .
$$

Thereby, a lower bound for the switching frequency $f_{\mathrm{s}}$ is calculated. It is noted that a high-speed motor drive, which features a high fundamental frequency e.g., $f_{\mathrm{m}}=5 \mathrm{kHz}$, also requires a high switching frequency e.g., $f_{\mathrm{s}} \geqslant a_{\mathrm{f}}^{2} f_{\mathrm{m}}=245 \mathrm{kHz}$. A comprehensive design algorithm for the output filter, tailored to high-speed motor drives, is presented in Appendix A more general design algorithm, also applicable to conventional lowspeed motor drives, is described in the following.

The c-FSF comprises three individual inductors $L_{\mathrm{m}}$, each corresponding to one phase-leg. For a filter inductor $L_{\mathrm{m}}$ the 
maximum inductor current ripple amplitude (single-side) $\Delta I_{L \mathrm{~m}}$ can be calculated as

$$
\Delta I_{L \mathrm{~m}}=\frac{U_{\mathrm{pn}}}{8 L_{\mathrm{m}} f_{\mathrm{s}}} .
$$

Accordingly, in order to limit the current ripple to a maximum value $\Delta I_{L \mathrm{~m}}$ then the inductor $L_{m}$ value should be

$$
L_{\mathrm{m}} \geqslant \frac{U_{\mathrm{pn}}}{8 \Delta I_{L \mathrm{~m}} f_{\mathrm{s}}} .
$$

The maximum occurring voltage ripple amplitude (single-side) $\Delta U_{\mathrm{Cm}}$ at the output filter capacitor $C_{\mathrm{m}}$ is

$$
\Delta U_{\mathrm{Cm}}=\frac{\Delta I_{L \mathrm{~m}}}{8 C_{\mathrm{m}} f_{\mathrm{s}}} \stackrel{(37)}{=} \frac{U_{\mathrm{pn}}}{64 f_{\mathrm{s}}^{2} L_{\mathrm{m}} C_{\mathrm{m}}}=\frac{\pi^{2}}{16}\left(\frac{f_{\mathrm{r}, \mathrm{DMlc} c \mathrm{FSF}}}{f_{\mathrm{s}}}\right)^{2} U_{\mathrm{pn} .}
$$

Accordingly, in order to limit the voltage ripple to a maximum value of $\Delta U_{\mathrm{Cm}} \leqslant 1 \mathrm{~V}$, which is safe for the motor operation, the capacitance $C_{\mathrm{m}}$ values should be

$$
C_{\mathrm{m}} \geqslant \frac{U_{\mathrm{pn}}}{64 f_{\mathrm{s}}^{2} L_{\mathrm{m}} \Delta U_{\mathrm{Cm}}} .
$$

The d-FSF comprises only one three-phase choke. The CM inductance of the choke $L_{\mathrm{m}, \mathrm{CM}}$ is used for CM attenuation, while the leakage inductance of the choke $L_{\mathrm{m}, \mathrm{DM}}$ is used for DM attenuation [42], [43]. The d-FSF is designed, similarly to the c-FSF filter. The same DM resonant frequency $f_{\mathrm{r}, \mathrm{DN} d \mathrm{~d}-\mathrm{sSF}}$ constraints of (35) and switching frequency constraint of (36) apply for the d-FSF. Furthermore, the output filter DM inductor constraint of (38) and DM capacitor constraint of (40) are extended for the d-FSF

$$
L_{\mathrm{m}, \mathrm{DM}} \geqslant \frac{U_{\mathrm{pn}}}{8 \Delta I_{\mathrm{Lm}, \mathrm{DM}} f_{\mathrm{s}}}, \quad C_{\mathrm{m}, \mathrm{DM}} \geqslant \frac{U_{\mathrm{pn}}}{64 f_{\mathrm{s}}^{2} L_{\mathrm{m}} \Delta U_{C_{\mathrm{m}, \mathrm{MM}}}} .
$$

The d-FSF should not interfere with the third harmonic CM voltage $u_{\overline{\mathrm{i}}, \mathrm{CM} / \mathrm{fm}}(5)$ of the THM modulation strategy (1). Based on this objective, the CM resonant frequency is selected to be similar to the DM resonant frequency $f_{\mathrm{r}, \mathrm{CM}(\mathrm{d}-\mathrm{Fs}} \cong f_{\mathrm{r}, \mathrm{DM} d \mathrm{~d}-\mathrm{FS}}$ (35). The inductance of the CM choke $L_{\mathrm{m}, \mathrm{CM}}$ is typically two orders of magnitude larger than its DM leakage inductance $L_{\mathrm{m}, \mathrm{DM}}$ [42], [43]. Therefore, a small CM capacitance $C_{\mathrm{m}, \mathrm{CM}}$ must be selected in order to counterbalance the high CM choke inductance value $L_{\mathrm{m}, \mathrm{CM}}$

$$
L_{\mathrm{m}, \mathrm{CM}}=100 \cdot L_{\mathrm{m}, \mathrm{DM}}, C_{\mathrm{m}, \mathrm{CM}}=C_{\mathrm{m}, \mathrm{DM}} / 100 .
$$

The above output filter design guidelines (38), (40)-(42) depend on the switching frequency $f_{\mathrm{s}}$. The switching frequency represents a crucial design trade-off. A high switching frequency allows to reduce the volume of the passive filter components, but at the same time increases the semiconductor switching losses and accordingly requires a larger semiconductor heatsink volume. The (36) only provides a lower bound for the switching frequency $f_{\mathrm{s}}$, but does not explicitly define it. In order to select an appropriate switching frequency, a multi-objective optimization routine, with respect to inverter efficiency $\eta$ and power density $\rho$, is employed [44], [45], which assesses the performance of several inverter designs. The optimization routine includes the inductive components (inductors $L_{\mathrm{m}}$, threephase choke $L_{\mathrm{m}, \mathrm{CM}}$ ) [42], [46], [47], the ceramic filter capacitors, the $200 \mathrm{~V}$ rated GaN semiconductor devices [48] and the semiconductor heatsinks [49]. Based on the optimization results, a switching frequency of $f_{\mathrm{s}}=350 \mathrm{kHz}$ is selected. This switching frequency is 70 times higher than the fundamental frequency of the motor $f_{\mathrm{m}}=5 \mathrm{kHz}$, a fact that enables a highly dynamic motor control. A design guideline summary for the c-FSF and d-FSF and the selected benchmark designs are given in Table II.

\section{B. Input Filter}

A two-stage input filter is now designed. The conducted EMI emissions are regulated in the frequency range of $150 \mathrm{kHz}^{-}$ $30 \mathrm{MHz}$. In this range, the critical frequency $f_{\mathrm{c}}=n f_{\mathrm{s}}$, which is related to the worst case EMI noise, is identified. The order $n$ of the critical frequency is

$$
n=\left\lceil\frac{150 \mathrm{kHz}}{f_{\mathrm{s}}}\right\rceil .
$$

For the inverter system at hand, the switching frequency is $f_{\mathrm{s}}=$ $350 \mathrm{kHz}$, which exceeds $150 \mathrm{kHz}$, hence the critical frequency is $f_{\mathrm{c}}=f_{\mathrm{s}}$, i.e., $n=1$.

The input filter design algorithm, assumes an installed FSF (c-FSF or d-FSF). As shown in (19), a FSF result in a low equivalent CM noise source $u_{\overline{\mathrm{p}}, \mathrm{CM} / \mathrm{s} s}$ at the input. Thereafter, an FSF reduces the input CM EMI emissions and allows for a smaller input EMI filter. In this case, the minimum required input filter $\mathrm{CM}$ attenuation $(\mathrm{dB})$ at the critical frequency $f_{\mathrm{c}}$ is

$$
\begin{aligned}
A_{\mathrm{CM}}(\mathrm{dB}) & =U_{\text {limit }}-10-6-20 \log \left(\frac{\left\lceil\hat{U}_{\overline{\mathrm{pn}}, \mathrm{CM} / \mathrm{s}}\right]\left(n f_{\mathrm{s}}\right)}{10^{-6} \sqrt{2}}\right) \\
\stackrel{(19)}{=} & 63-20 \log \left(\frac{1}{10^{-6} \sqrt{2}} \frac{c_{\mathrm{s}}}{C_{\mathrm{pn}, \mathrm{CM}, 0}+c_{\mathrm{s}}} \frac{2 U_{\mathrm{pn}}}{n \pi}\right),
\end{aligned}
$$

where $U_{\text {limit }}=79 \mathrm{~dB} \mu \mathrm{V}$ is the limit mandated at $f=350 \mathrm{kHz}$ by the EMI regulations. Additionally $10 \mathrm{~dB} \mu \mathrm{V}$ are subtracted in order to account for component tolerances and further $6 \mathrm{~dB} \mu \mathrm{V}$ are subtracted in order to ensure that both $50 \Omega$ LISN branches comply with the EMI regulations. Subsequently, the minimum required DM filter attenuation $(\mathrm{dB})$ at the critical frequency $f_{\mathrm{c}}$ is derived

$$
\begin{aligned}
& A_{\mathrm{DM}}(\mathrm{dB})=U_{\text {limit }}-10-20 \log \left(\frac{\left[\hat{U}_{\overline{\mathrm{pn}}, \mathrm{DM} / \mathrm{s}}\right]\left(n f_{\mathrm{s}}\right)}{10^{-6} \sqrt{2}}\right) \\
& \stackrel{(28)}{=} 69-20 \log \left(\frac{1}{10^{-6} \sqrt{2}} \frac{2 \hat{I}_{\mathrm{m}}}{n \pi} \frac{1}{2 \pi f_{\mathrm{s}} C_{\mathrm{pn}, \mathrm{DM}, 0}}\right)(
\end{aligned}
$$


TABLE II

Design Summary for an Output FSF. Numeric Values Are Given for a System With the Specifications of Table I

\begin{tabular}{lllll}
\hline \hline & \multicolumn{1}{c}{ Output c-FSF } & \multicolumn{1}{c}{ Output d-FSF } \\
\hline Switching freq. & $(36)$ & $f_{\mathrm{s}}=350 \mathrm{kHz}, a_{\mathrm{f}}=7$ & $(36)$ & $f_{\mathrm{s}}=350 \mathrm{kHz}, a_{\mathrm{f}}=7$ \\
DM resonant freq. & $(14)$ & $\left.f_{\mathrm{r}, \mathrm{DM}}\right|_{\mathrm{c}-\mathrm{FSF}}=50 \mathrm{kHz}$ & $(21)$ & $\left.f_{\mathrm{r}, \mathrm{DM}}\right|_{\mathrm{d}-\mathrm{FSF}}=50 \mathrm{kHz}$ \\
DM attenuation & $(13)$ & $\left.A_{\mathrm{DM}}\right|_{\mathrm{c}-\mathrm{FSF}}\left(f_{\mathrm{s}}\right)=-33.5 \mathrm{~dB}$ & $(20)$ & $\left.A_{\mathrm{DM}}\right|_{\mathrm{d}-\mathrm{FSF}}\left(f_{\mathrm{s}}\right)=-33.5 \mathrm{~dB}$ \\
$\mathrm{CM}$ resonant freq. & $(17)$ & $\left.f_{\mathrm{r}, \mathrm{CM}}\right|_{\mathrm{c}-\mathrm{FSF}}=50 \mathrm{kHz}$ & $(24)$ & $\left.f_{\mathrm{r}, \mathrm{CM}}\right|_{\mathrm{d}-\mathrm{FSF}}=50 \mathrm{kHz}$ \\
$\mathrm{CM}$ attenuation & $(16)$ & $\left.A_{\mathrm{CM}}\right|_{\mathrm{c}-\mathrm{FSF}}\left(f_{\mathrm{s}}\right)=-33.5 \mathrm{~dB}$ & $(23)$ & $\left.A_{\mathrm{CM}}\right|_{\mathrm{d}-\mathrm{FSF}}\left(f_{\mathrm{s}}\right)=-33.5 \mathrm{~dB}$ \\
Inductance & $(38)$ & $L_{\mathrm{m}}=5 \mu \mathrm{H}, \Delta I_{L_{\mathrm{m}}}=5.7 \mathrm{~A}$ & $(41)$ & $L_{\mathrm{m}, \mathrm{DM}}=5 \mu \mathrm{H}, \Delta I_{L_{\mathrm{m}, \mathrm{DM}}}=5.7 \mathrm{~A}$ \\
& & $(42)$ & $L_{\mathrm{m}, \mathrm{CM}}=0.5 \mathrm{mH}$ \\
Capacitance & $(40)$ & $C_{\mathrm{m}}=2 \mu \mathrm{F}, \Delta U_{C_{\mathrm{m}}}=1 \mathrm{~V}$ & $(41)$ & $C_{\mathrm{m}, \mathrm{DM}}=2 \mu \mathrm{F}, \Delta U_{C_{\mathrm{m}, \mathrm{DM}}}=1 \mathrm{~V}$ \\
& & & $(42)$ & $C_{\mathrm{m}, \mathrm{CM}}=20 \mathrm{nF}$ \\
\hline \hline
\end{tabular}

The required minimum DM attenuation $A_{\mathrm{DM}}$ is independent of the installed output filter (DMF or FSF). Accordingly, the input filter maximum allowed $\mathrm{DM} / \mathrm{CM}$ resonant frequencies per stage are

$$
f_{\mathrm{r}, \mathrm{DM}}=f_{\mathrm{s}} \sqrt[4]{A_{\mathrm{DM}}}, f_{\mathrm{r}, \mathrm{CM}}=f_{\mathrm{s}} \sqrt[4]{A_{\mathrm{CM}}}
$$

The input filter design is summarized in Table III.

A benchmark two-stage input filer design is selected in Table III. The input filter inductance $\left(L_{\mathrm{pn}, \mathrm{DM}, \mathrm{k}}, L_{\mathrm{pn}, \mathrm{CM}, \mathrm{k}}\right)$ and capacitance $\left(C_{\mathrm{pn}, \mathrm{DM}, \mathrm{k}}, C_{\mathrm{pn}, \mathrm{CM}, \mathrm{k}}\right)$ values of the benchmark design are selected such that the overall input filter volume is minimized [50]. A toroidal choke with two windings is used for the realization of the $\mathrm{CM}$ inductor $L_{\mathrm{pn}, \mathrm{CM}, \mathrm{k}}$. The stray inductance of each winding is used as DM inductance $L_{\mathrm{pn}, \mathrm{DM}, \mathrm{k}}$. The selected total input filter $\mathrm{CM}$ capacitance $C_{\mathrm{pn}, \mathrm{CM}}=C_{\mathrm{pn}, \mathrm{CM}, 0}+C_{\mathrm{pn}, \mathrm{CM}, 1}+$ $C_{\mathrm{pn}, \mathrm{CM}, 2}=100 \mathrm{nF}$ is very large. This large CM capacitance is only allowed in the case of motor drives supplied by a DC source (cf., Fig. 1). There, no low-frequency ground currents flow through the input filter CM capacitors $C_{\mathrm{pn}, \mathrm{CM}, \mathrm{k}}$. On the contrary, if a single-phase grid would supply the motor drive, then large CM currents would flow through the capacitors $C_{\mathrm{pn}, \mathrm{CM}, \mathrm{k}}$, that would violate the $3.5 \mathrm{~mA}$ limit, mandated by [3].

\section{EXPERIMENTAL VALIDATION}

In order to validate the proposed filter concepts, an inverter prototype is assembled for a $P=1 \mathrm{~kW}, n=280 \mathrm{krpm}$ highspeed motor drive, with the specifications of Table I. The hardware prototype PCB assembly is presented in Fig. 6(a). The experimental setup features a modular design, i.e., multiple interchangeable boards are connected together. The input filter board and the corresponding component values (measured) are depicted in Fig. 6(b). The designed power board, employing the latest generation of $200 \mathrm{~V}$ rated GaN semiconductor devices, is depicted in Fig. 6(c). The power board also includes the DC link, i.e., the input filter DM capacitor $C_{\mathrm{pn}, \mathrm{DM}, 0}$ and the CM capacitors $C_{\mathrm{pn}, \mathrm{CM}, 0}$. Placing these filter capacitors close to the semiconductor devices minimizes the parasitic inductances and therefore improves the EMI performance. The c-FSF and
d-FSF boards, as well as the component values (measured) are illustrated in Fig. 6(d.i) and (d.ii), respectively. It is noted, that the c-FSF board can be reconfigured as a simple DMF (cf., Fig. 2). A control board is vertically attached to the PCB assembly and finally a custom heatsink, an active thermal management system and a metallic housing are added. The assembled hardware demonstrator is shown in Fig. 7. A grounded metallic housing is mandatory for end user safety and is a common practice in drive systems. Furthermore, the grounded housing contributes to the parasitic capacitance formation, hence must be used for meaningful EMI noise measurements.

The c-FSF uses three ELP inductors $L_{\mathrm{m}}$ (cf., Fig. 6(d.i)), which require a total volume of $12.7 \mathrm{~cm}^{3}$. The efficiency of the whole inverter system with an installed c-FSF is $96.6 \%$. In comparison, the d-FSF uses one three-phase choke $L_{\mathrm{m}, \mathrm{CM}}$ (cf., Fig. 6(d.ii)), which requires a volume of $11.1 \mathrm{~cm}^{3}$, The leakage inductance of the three-phase choke is used as the d-FSF DM inductor $L_{\mathrm{m}, \mathrm{DM}}$ (i.e. no dedicated DM inductors) [42], [43]. The lower volume for the d-FSF is achieved thanks to the VAC 500 F nanocrystalline magnetic material [51], used for the toroidal core. This material features a high saturation flux density of $\hat{B}_{\mathrm{s}}$ $=1 \mathrm{~T}$, which allows for a compact realization of the three-phase choke. In contrast, the c-FSF uses ELP cores, made of N87 ferrite material, which features a saturation flux density of only $\hat{B}_{\mathrm{s}}=350 \mathrm{mT}$. This low saturation flux density, leads to a bulkier realization of the c-FSF. The efficiency of the whole inverter stage with an installed d-FSF is $96.1 \%$. The high losses of the d-FSF (+5 W compared to c-FSF) originate from the threephase CM choke windings. All the three-phase winding must mechanically fit within the inner diameter of the CM choke. Due to the limited available space, thinner wires must be used which accordingly result in high conduction losses.

\section{A. Filter Attenuation Measurements}

The attenuation of the input/output filter boards is experimentally measured, with a frequency response analyser, as is illustrated in Fig. 8. The c-FSF board attenuation is first measured. Namely, the DM attenuation $A_{\text {DMlc-FSF }}$ measurement (13) is shown in Fig. 9(a), while the CM attenuation $A_{\mathrm{CM} / \mathrm{c}-\mathrm{FSF}}$ measurement (16) is depicted in Fig. 9(b). For low frequencies 
TABLE III

Design Summary for an Input Filter With Minimum Volume and Assuming an Installed Output FSF (c-FSF or d-FSF). Numeric Values Are Given for a System With THE SPECIFICATIONS OF TABLE I.

\begin{tabular}{lllll}
\hline \hline & & DM input filter & & \multicolumn{1}{c}{ CM input filter } \\
\hline Critical frequency & $(43)$ & $f_{\mathrm{c}}=n f_{\mathrm{s}}=350 \mathrm{kHz}, n=1$ & (43) & $f_{\mathrm{c}}=n f_{\mathrm{s}}=350 \mathrm{kHz}, n=1$ \\
Filter stages & & $N=2$ & & $N=2$ \\
Min. attenuation & $(45)$ & $A_{\mathrm{DM}}=-37.9 \mathrm{~dB}$ & (44) & $A_{\mathrm{CM}}=-37.7 \mathrm{~dB}$ \\
Max. resonant freq. & $(46)$ & $f_{\mathrm{r}, \mathrm{DM}}=117.7 \mathrm{kHz}$ & $(46)$ & $f_{\mathrm{r}, \mathrm{CM}}=118.1 \mathrm{kHz}$ \\
Inductance & & $L_{\mathrm{pn}, \mathrm{DM}, \mathrm{k}}=0.15 \mu \mathrm{H}$ & & $L_{\mathrm{pn}, \mathrm{CM}, \mathrm{k}}=65 \mu \mathrm{H}$ \\
Capacitance & & $C_{\mathrm{pn}, \mathrm{DM}, \mathrm{k}}=17 \mu \mathrm{F}$ & & $C_{\mathrm{pn}, \mathrm{CM}, \mathrm{k}}=33 \mathrm{nF}$ \\
Resonant freq. & $(30)$ & $f_{\mathrm{r}, \mathrm{DM}}=99.7 \mathrm{kHz}$ & (33) & $f_{\mathrm{r}, \mathrm{CM}}=108.7 \mathrm{kHz}$ \\
Attenuation & $(29)$ & $A_{\mathrm{DM}}=-43.9 \mathrm{~dB}$ & (32) $A_{\mathrm{CM}}=-40.6 \mathrm{~dB}$ \\
\hline \hline
\end{tabular}

A parasitic capacitance of the semiconductor devices $c_{\mathrm{s}}=100 \mathrm{pF}$, is assumed.

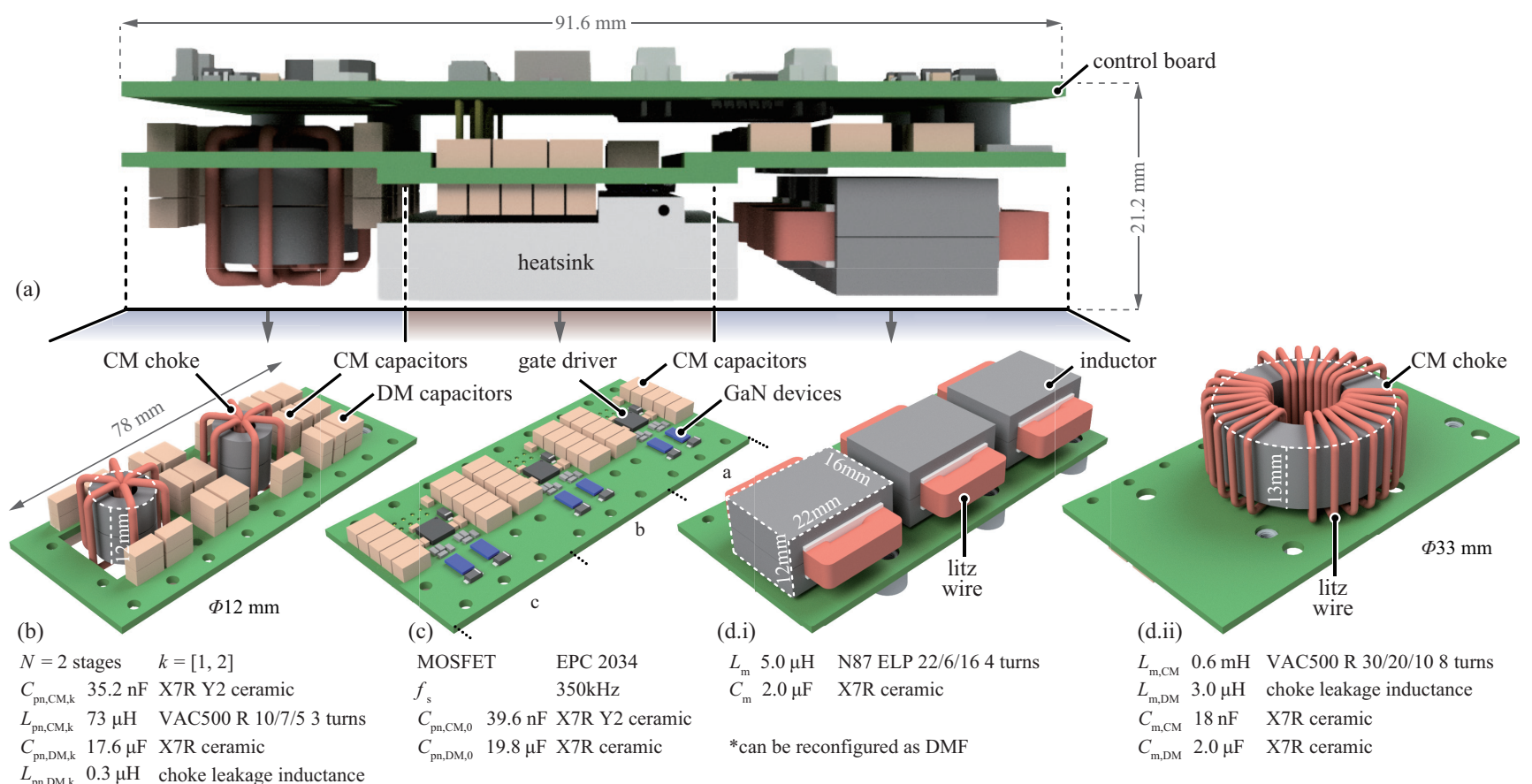

Fig. 6. (a) Modular inverter hardware prototype. (b) Two-stage input filter followed by (c) power board. (d.i) c-FSF (cf., Fig. 3) and (d.ii) d-FSF (cf., Fig. 4). The c-FSF can be reconfigured into a DMF (cf., Fig. 2). The measured component values slightly differ from the theoretical values given in Table. II and III, due to nonidealities in the manufacturing.

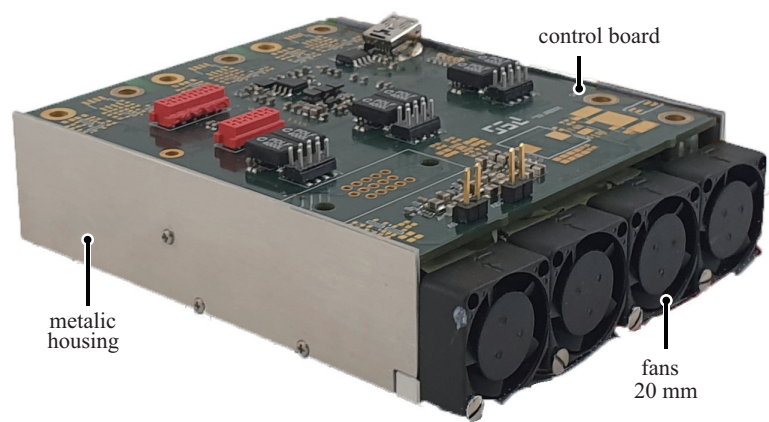

Fig. 7. Inverter hardware prototype with dimensions $99.6 \mathrm{~mm} \times 80 \mathrm{~mm} \times$ $23.7 \mathrm{~mm}$. A power density of $5.8 \mathrm{~kW} / \mathrm{dm}^{3}\left(95 \mathrm{~W} / \mathrm{in}^{3}\right)$ is achieved. $f$ both the DM attenuation $A_{\text {DMC-rss }}$ and the CM attenuation $A_{\text {cMlc- }}$ FsF match well with the theoretical approximation. However, for high frequencies $f>4 \mathrm{MHz}$ the $\mathrm{CM}$ attenuation $A_{\text {cmlc- }}$ ${ }_{\text {FsF }}$ of Fig. 9(b) diverges from the theoretical approximation. In this frequency range, the CM performance of the c-FSF is degrading due to parasitic effects, i.e., self-resonance of the employed passive components and/or parasitic mutual coupling between the passive components [52].

Subsequently, the d-FSF is measured. The DM attenuation $A_{\text {DMld-FS }}(20)$ is illustrated in Fig. 10(a). The theoretical approximation matches well the experimental measurement for low frequencies, but diverges for high frequencies $f>1$ $\mathrm{MHz}$, due to parasitic effects. It is noted, that by shorting two out of the three windings of the $\mathrm{CM}$ choke in the measurement 


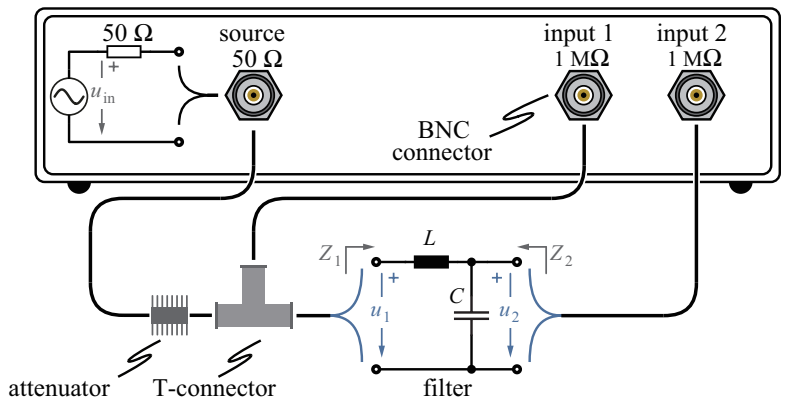

Fig. 8. Measurement setup for a filter transfer function, featuring the Omicron Labs Bode 100 frequency response analyser.

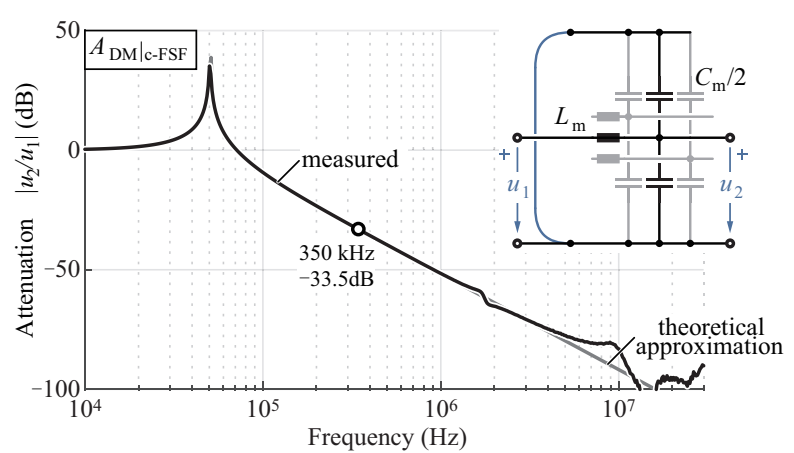

(a)

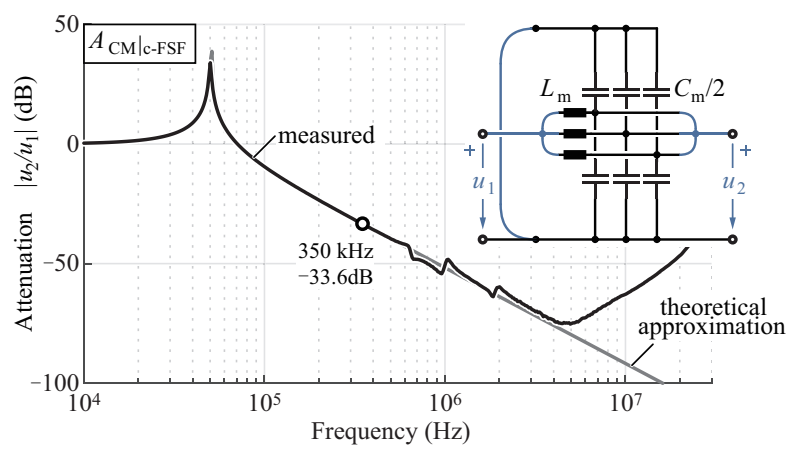

(b)

Fig. 9. c-FSF: (a) DM attenuation $A_{\mathrm{DM} \mid \mathrm{c}-\mathrm{FSF}}(f)$ and (b) CM attenuation $A_{\mathrm{CM} \mid \mathrm{c}-\mathrm{FSF}}(f)$. The measured attenuation is compared against a theoretical approximation assuming constant $L_{\mathrm{m}}=5 \mu \mathrm{H}$ and $C_{\mathrm{m}}=2 \mu \mathrm{F}$, with respect to frequency $f$ (cf., Fig. 6(d.i)).

setup of Fig. 10(a), a leakage inductance of $1.5 \mathrm{~L}_{\mathrm{m}, \mathrm{DM}}$ results. Therefore, this experimental setup does not correspond to the exact DM attenuation $A_{\mathrm{DM} d \mathrm{~d}-\mathrm{ss}}$, which would require a leakage inductance of exactly $L_{\mathrm{m}, \mathrm{DM}}$. However, the difference between the depicted DM attenuation measurement and the real DM attenuation is only $-3 \mathrm{~dB}$.

The CM attenuation $A_{\text {cyld-ss }}(23)$ is plotted in Fig. 10(b), The depicted theoretical approximation assumes a constant $\mathrm{CM}$ inductance $L_{\mathrm{m}, \mathrm{CM}}=600 \mu \mathrm{H}$ and CM capacitance $C_{\mathrm{m}, \mathrm{CM}}=18 \mathrm{nF}$ (cf., Fig. 6(d.ii)), hence, in the cut-off region of the filter $f>50$ $\mathrm{kHz}$ the attenuation drops with a slope of $-40 \mathrm{~dB}$ per frequency decade $f$. However, this does not agree with the measured attenuation profile which drops with a slope close to $-30 \mathrm{~dB}$ per frequency decade $f$. This difference between the slope of

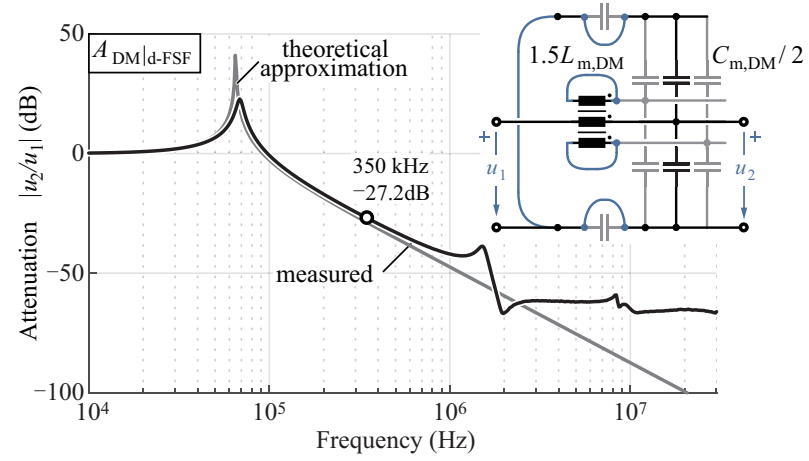

(a)

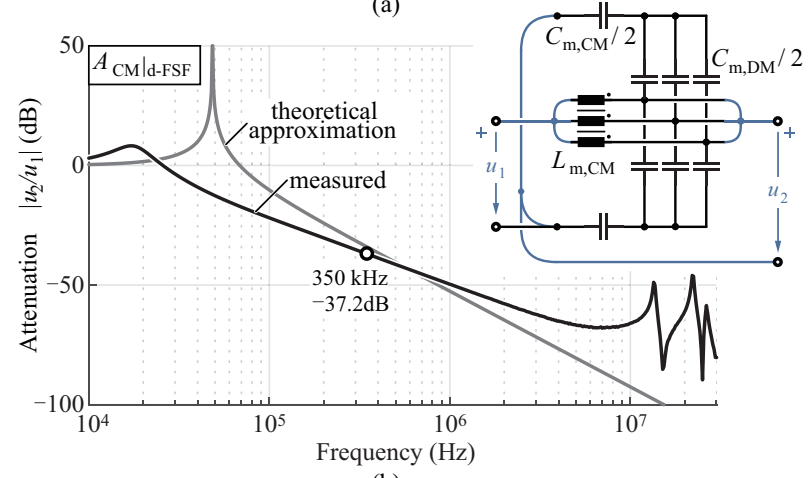

(b)

Fig. 10. d-FSF: (a) DM attenuation $A_{\text {DMld-ss }}(f)$ and (b) CM attenuation $A_{\text {CMId- }}$ ${ }_{\mathrm{FSF}}(f)$. The measured attenuation is compared against a theoretical approximation assuming constant $L_{\mathrm{m}, \mathrm{DM}}=3 \mu \mathrm{H}, C_{\mathrm{m}, \mathrm{DM}}=2 \mu \mathrm{F}, L_{\mathrm{m}, \mathrm{CM}}=600 \mu \mathrm{H}$ and $C_{\mathrm{m}, \mathrm{CM}}=18$ $\mathrm{nF}$, with respect to frequency $f$ (cf., Fig. 6(d.ii)).

the theoretical approximation and the measurement is caused by the non-linear, frequency dependent behaviour of the CM choke inductance $L_{\mathrm{m}, \mathrm{CM}}(f)$. In particular, the three-phase choke employs the nanocrystalline core material VAC 500F [51], whose imaginary magnetic permeability $\mu^{\prime \prime}$ dominates for frequencies $f>20 \mathrm{kHz}$ [53]. As a result, the CM inductor, exhibits a highly resistive, frequency dependent behaviour $L_{\mathrm{m}, \mathrm{CM}}(f)$ [54]. Hence, the measured CM attenuation profile $A_{\mathrm{CM} \text { ld-FSF }}(f)(-30 \mathrm{~dB}$ per frequency decade) lies in between a first order RC filter (-20dB per frequency decade) and an LC filter $(-40 \mathrm{~dB}$ per frequency decade). It is noted, that the nonlinearity of the core material is taken into account in the design process of the three-phase choke. Thus, for the frequency $f_{\mathrm{s}}=$ $350 \mathrm{kHz}$, for which the d-FSF is designed, the measured CM attenuation $A_{\mathrm{CM} \mid \mathrm{d}-\mathrm{FSF}}$ and the theoretical approximation match well.

Finally, the input filter board attenuation is measured. In Fig. 11(a) the DM attenuation $A_{\mathrm{DM}}$ (29) is measured. The DM attenuation $A_{\mathrm{DM}}$ diverges from the theoretical approximation for frequencies $f>700 \mathrm{kHz}$, due to parasitic effects [52]. Furthermore, the measured DM attenuation $A_{\mathrm{DM}}$ exhibits two pronounced resonances, a fact that is expected in a twostage filter (29). The CM attenuation $A_{\mathrm{CM}}$ (32) is measured in Fig. 11(b). The depicted theoretical approximation assumes a constant CM inductance $L_{\mathrm{pn}, \mathrm{CM}, \mathrm{k}}=73 \mu \mathrm{H}$ and CM capacitance $C_{\mathrm{pn}, \mathrm{CM}, \mathrm{k}}=35.2 \mathrm{nF}$ (cf., Fig. 6(b)). Hence, in the cut-off region 

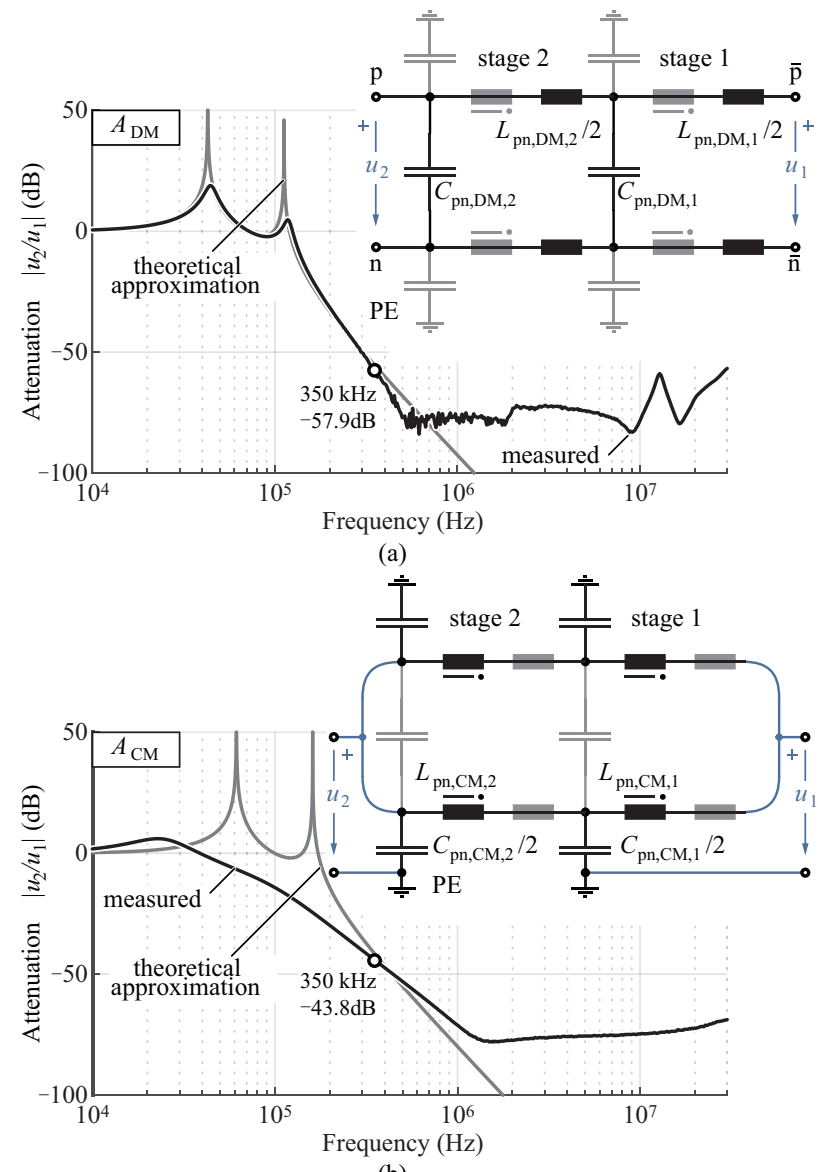

(b)

Fig. 11. Input filter: (a) DM attenuation $A_{\mathrm{DM}}(f)$ and (b) $\mathrm{CM}$ attenuation $A_{\mathrm{CM}}(f)$. The measured attenuation is compared against a theoretical approximation assuming constant $L_{\mathrm{pn}, \mathrm{DM}, \mathrm{k}}=0.3 \mu \mathrm{H}, C_{\mathrm{pn}, \mathrm{DM}, \mathrm{k}}=17.6 \mu \mathrm{F}, L_{\mathrm{pn}, \mathrm{CM}, \mathrm{k}}=73 \mu \mathrm{H}$ and $C_{\mathrm{pn}, \mathrm{CM}, \mathrm{k}}=35.2 \mathrm{nF}$, with respect to frequency $f$ (cf., Fig. $6(\mathrm{~b})$ ).

of the two-stage filter $f>150 \mathrm{kHz}$ the attenuation drops with a slope of $-80 \mathrm{~dB}$ per frequency decade $f$. However, this does not agree with the measured attenuation profile which drops with a slope close to $-60 \mathrm{~dB}$ per frequency decade $f$. As explained before, this difference is expected, due to the highly non-linear, resistive nature of the material VAC 500F [51], used for the realization of the CM choke $L_{\mathrm{pn}, \mathrm{CM}, \mathrm{k}}$. The $\mathrm{CM}$ inductor behaves resistively for frequencies $f>20 \mathrm{kHz}$, thus the $\mathrm{CM}$ resonance of the filter is highly damped and the attenuation drops with a slope close to $-60 \mathrm{~dB}$ per frequency decade. However, a good match between the measured and theoretical $\mathrm{CM}$ attenuation $A_{\mathrm{CM}}$ is evident for the switching frequency $f_{\mathrm{s}}=350 \mathrm{kHz}$, for which the input filter is designed.

\section{B. Parasitic CM Impedance Measurements}

The different parasitic capacitances which conduct CM EMI currents are measured with an impedance analyser. Firstly, the motor-inverter interface cable $\mathrm{CM}$ parasitic capacitance $c_{\mathrm{c}}$ is measured (cf., Fig. 1). A shielded cable, featuring four 2.5 $\mathrm{mm}^{2}$ conductors, is used. In particular, the three conductors correspond to the three phases $a, b$ and $c$ while the fourth

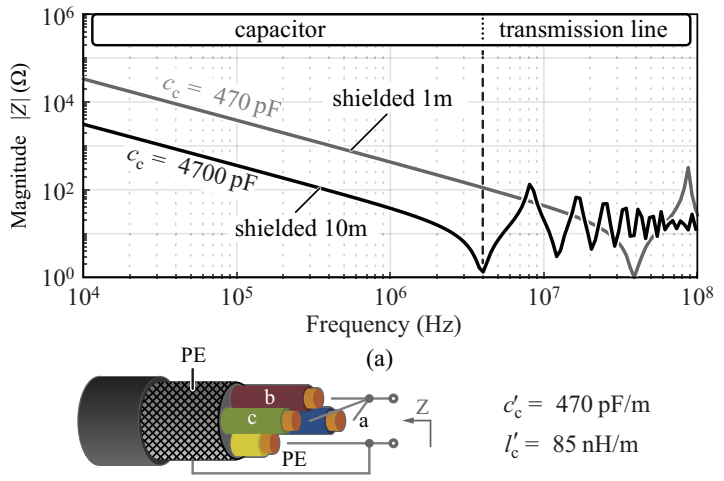

(b)

Fig. 12. (a) CM impedance measurement results for $1 \mathrm{~m}$ and $10 \mathrm{~m}$ shielded cables. (b) Cable CM impedance measurement setup, using the Keysight 4294A impedance analyser.

conductor is used exclusively for PE. In order to measure the shielded cable CM impedance, one side of the cable is connected to the impedance analyser, which measures its impedance $Z$ over frequency $f$, while the other side of the cable is an open circuit as illustrated in Fig. 12(b). The impedance measurement results for $1 \mathrm{~m}$ and $10 \mathrm{~m}$ shielded cables are plotted Fig. 12(a). For low frequencies the capacitive behaviour $c_{\mathrm{c}}$ of the cable is dominant, while for high frequencies $(f>$ $2 \mathrm{MHz}$ for the example case of the $10 \mathrm{~m}$ cable) the cables behave as a transmission line (terminated with open circuit). The impedance measurement results reveal that the total $\mathrm{CM}$ capacitance is proportional to the length of the cable and hence the normalized cable CM capacitance is $c_{\mathrm{c}}^{\prime}=470 \mathrm{pF} / \mathrm{m}$. In commercial motor drives, shielded cables have found wide acceptance, while unshielded cables are typically not preferred. The reason behind the popularity of the shielded cables is the radiated EMI noise certification [55], [56]. Namely, the shield of a shielded cable allows for a good PE connection between the inverter and the motor and mitigates the radiated EMI emissions.

Subsequently, the CM parasitic capacitance of the motor/ compressor $c_{\mathrm{m}}$ is measured and is equal to $c_{\mathrm{m}}=850 \mathrm{pF}$. The $1 \mathrm{~kW} 280 \mathrm{krpm}$ electric compressor [57] is shown in Fig. 13(b), while the impedance measurement is depicted in Fig. 13(a). A resistive load substitutes the electric compressor during the EMI measurements, for practical reasons. The $\mathrm{CM}$ parasitic capacitance of the resistive load is $c_{\mathrm{m}}=650 \mathrm{pF}$, while the impedance measurement is illustrated in Fig. 13(a). The CM impedance of the resistive load is very similar to the respective motor $\mathrm{CM}$ parasitic impedance, therefore both loads behave similarly in terms of EMI.

It is difficult to measure the parasitic capacitance $c_{\mathrm{s}}$ of the semiconductor devices. Low-voltage GaN devices feature very compact ceramic packaging, hence $c_{\mathrm{s}}$ is very small. In this case, other factors, such as the PCB layout, the placement of the passive components and the housing, signicantly affect the $c_{\mathrm{s}}$ parasitic capacitance value. For this reason, a conservative estimate of the semiconductor devices' parasitic capacitance of $c_{\mathrm{s}}=100 \mathrm{pF}$ is assumed. 

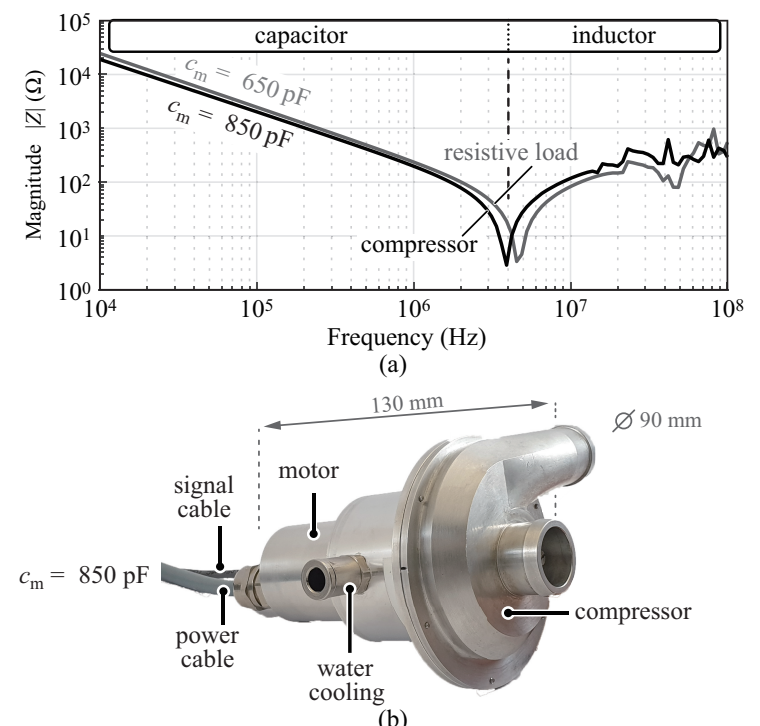

(b)

Fig. 13. (a) CM impedance measurement results and (b) $280 \mathrm{krpm}$ electric compressor [57]. The Keysight 4294A impedance analyser is used.

\section{Conducted EMI Measurements}

In a first step, the motor voltage quality is assessed. To this end, the test setup of Fig. 14 is employed, where the EMI emissions at the inverter output-side are measured. There, high output emissions are related to a poor motor voltage quality. Note that, the load current flows through the threephase LISN, which is designed for $50 \mathrm{~Hz}$ operation. Therefore, a low fundamental frequency of $f_{\mathrm{m}}=50 \mathrm{~Hz}$ must be used by the inverter stage, during the EMI measurements. The outputside EMI emissions, i.e., the sum of DM and CM emissions for phase-leg $a$, are shown in Fig. 15. No results are shown for the DMF, because the high CM EMI emissions in this case (11), would saturate/damage the LISN. For both c-FSF and d-FSF, the residual EMI emissions at the inverter output terminals $a$ are in the range of $1 \mathrm{~V}$. This voltage value does not electrically stress the motor and ensures a safe operation [22], [58]. However, the c-FSF achieves lower overall EMI emissions spectrum compared to the d-FSF, especially for higher frequencies. The worse d-FSF performance is partially explained by the inferior DM attenuation $A_{\mathrm{DM} / \mathrm{d}-\mathrm{FSF}}$ of the d-FSF (cf., Fig. 10(a)), compared to the respective DM attenuation $A_{\text {DMlc-FS }}$ of the c-FSF (cf., Fig. 9(a)).

However, the d-FSF suffers from an additional EMI performance problem, that is not captured by the attenuation measurements of Fig. 10. The DM inductance $L_{\mathrm{m}, \mathrm{DM}}=3 \mu \mathrm{H}$ is realized as the leakage inductance of the three-phase choke. By definition the high-frequency DM current ripple that flows through the leakage inductance, generates a DM magnetic fringing-filed that closes a path through the air around the choke [59]. This DM magnetic fringing field couples additional EMI noise to the surroundings of the choke, depending on the mechanical placement of the inverter components, and hence compromises the overall performance of the d-FSF. In contrast, the c-FSF does not suffer from this DM magnetic fringing filed

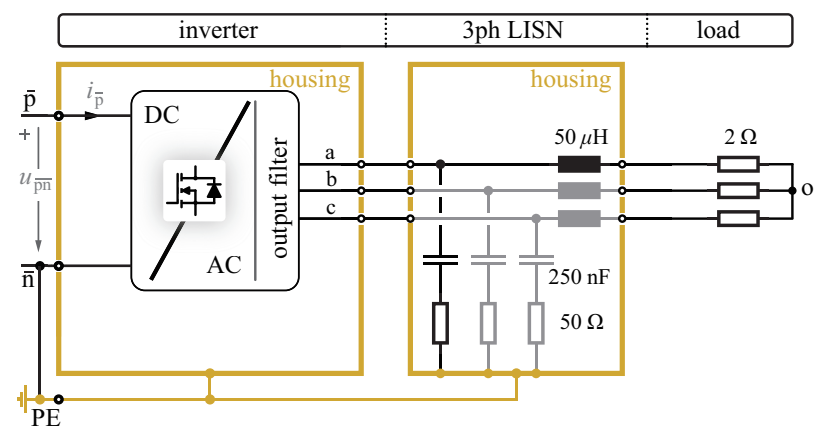

Fig. 14. Measurement setup for the EMI emissions at the inverter AC outputside. A three-phase LISN (Rohde \& Schwarz ENV432) is placed between the inverter and the load, and an EMI test receiver (Rohde \& Schwarz ESCI7) processes the LISN output $a$. No filter is installed at the input of the inverter and the negative DC rail $\bar{n}$ is shorted with PE.

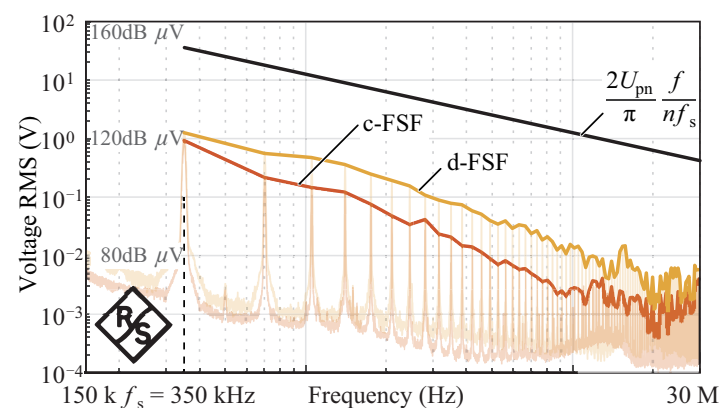

Fig. 15. Conducted EMI noise measurement results at the AC output-side, corresponding to the measurement setup of Fig. 14. The inverter transmits the full power and uses a fundamental frequency of $f_{\mathrm{m}}=50 \mathrm{~Hz}$. The conducted EMI noise is measured with an IEC 61800-3 quasi-peak (QP) detector and 4 $\mathrm{kHz}$ step size.

problem. The ELP cores employed for the realization of the filter inductors $L_{\mathrm{m}}$, enclose the windings and accordingly keep all the magnetic flux inside the core material.

In a second step, the inverter EMI emissions at the DC inputside are experimentally measured. To this end, the test setup of Fig. 16 is employed, while the input-side EMI measurement results are shown in Fig. 17. The results are presented for all analysed output filters (i.e., DMF, c-FSF or d-FSF), and for different shielded cable lengths (i.e., $1 \mathrm{~m}$ or $10 \mathrm{~m}$ ). Furthermore, the load is grounded only through the shielded cable, i.e., the dashed line of Fig. 16 can be neglected.

The simple DMF (considered for comparison purposes only) exhibits the worst performance. In this case, the motor drive fails to comply with the EMI regulations, due to excessive EMI noise across the whole frequency spectrum. The reason behind the low performance of the DMF, is its lack of CM attenuation (10). Excessive $\mathrm{CM} \mathrm{d} u / \mathrm{d} t$ is applied to the shielded cable/motor, thus high parasitic CM current flow through the cable/motor parasitic capacitances, towards PE. These parasitic currents form a return path from the DC input-side, thereby resulting in high CM EMI emissions at the input (cf., Fig. 2(a)). Furthermore, the severity of the input EMI emissions depends on the cable parasitic capacitance $c_{\mathrm{c}}$ value, which is linearly 


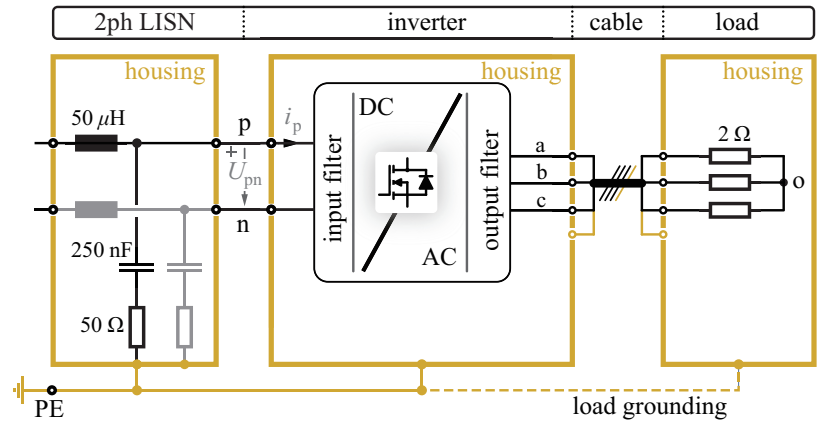

Fig. 16. Measurement setup for the EMI emissions at the inverter DC inputside. A two-phase LISN (Rohde \& Schwarz ENV432) is placed between the inverter and the DC power supply, and an EMI test receiver (Rohde \& Schwarz ESCI7) processes the LISN output $p$. The load can be either directly grounded (dashed yellow line applies) or only grounded through the shielded cable (dashed yellow line is neglected).
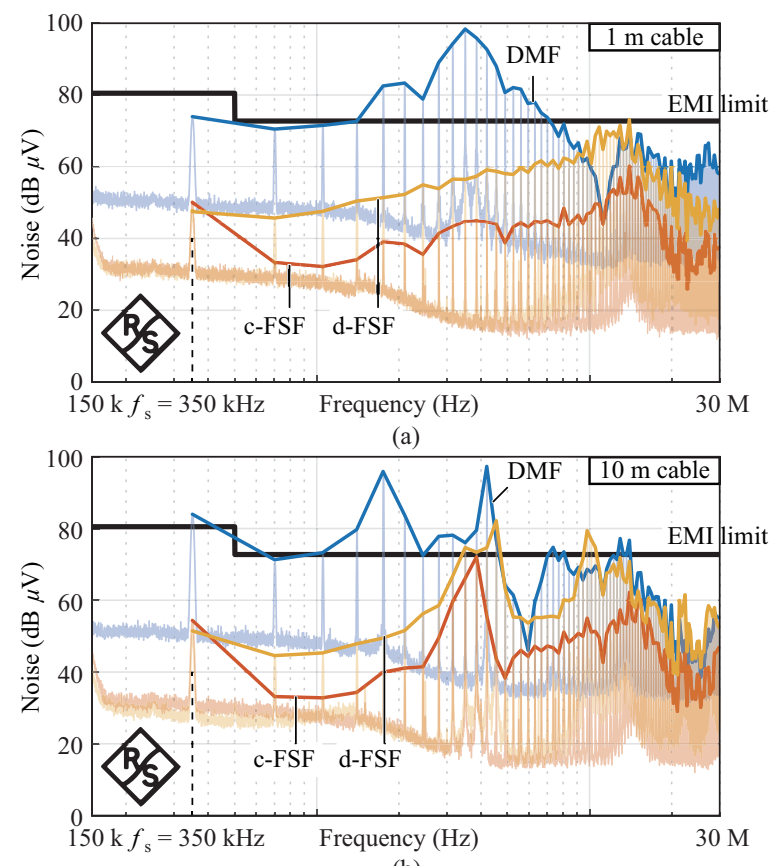

(b)

Fig. 17. Conducted EMI noise measurement results at the DC input-side for (a) $1 \mathrm{~m}$ shielded cable and (b) $10 \mathrm{~m}$ shielded cable. The results correspond to the measurement setup of Fig. 16 and the load is grounded only through the shielded cable. The inverter transmits the full power and uses a fundamental frequency of $f_{\mathrm{m}}=50 \mathrm{~Hz}$. The conducted EMI noise is measured with an IEC 61800-3 quasi-peak (QP) detector and $4 \mathrm{kHz}$ step size.

dependent on the cable length (cf., Fig. 12). In particular, the long $10 \mathrm{~m}$ cable causes $84 \mathrm{~dB} \mu \mathrm{V}$, opposed to $74 \mathrm{~dB} \mu \mathrm{V}$ caused by the short $1 \mathrm{~m}$ cable, at $350 \mathrm{kHz}$. Furthermore, the peaks of the EMI noise at $f>1 \mathrm{MHz}$ frequency range clearly correlate with the local minima of the corresponding cable impedances of Fig. 12. Besides high $\mathrm{d} u / \mathrm{d} t$ stress on the motor, a DMF results in an unwanted input-to-output CM noise mutual influence. Hence, the DMF should be avoided in WBG inverters.

The c-FSF achieves the best EMI performance and complies with EMI regulations at the input-side, regardless of the output-side cable configuration. In particular, the long $10 \mathrm{~m}$ cable causes $54 \mathrm{~dB} \mu \mathrm{V}$ at $350 \mathrm{kHz}$, which is close to the $50 \mathrm{~dB} \mu \mathrm{V}$ caused by the short $1 \mathrm{~m}$ cable. Besides a good motor voltage quality, the input EMI measurements highlight a second advantage of the c-FSF. The input-side EMI emissions are significantly lower and less dependent on the cable configuration, compared to a DMF. For this reasons, the c-FSF is an excellent choice for WBG inverters.

The d-FSF achieves an intermediate perfor-mance, i.e., worse performance than the c-FSF, but significantly better performance than the simple DMF. In particular, the c-FSF and d-FSF performances are similar at $350 \mathrm{kHz}$, for both the long $10 \mathrm{~m}$ and the short $1 \mathrm{~m}$ cables. However, as the frequency increases $(f>1 \mathrm{MHz})$ the d-FSF performance is degrading, resulting in roughly $10 \mathrm{~dB} \mu \mathrm{V}$ additional input EMI noise compared to the c-FSF. As a result, the d-FSF complies with the EMI regulations only for the short $1 \mathrm{~m}$ cable, but fails to comply with the EMI regulations for the long $10 \mathrm{~m}$ cable (at $f$ $=4 \mathrm{MHz}$ ). The main reason behind the worse performance of the d-FSF at high frequencies is the DM fringing flux of the three-phase choke. As discussed before, this DM fringing flux couples unwanted EMI noise to components in the vicinity of the choke, thereby increasing the overall EMI emissions. Purposely placed shielding around the choke, helps to reduce the unwanted DM fringing field but does not completely eliminate the problem. The alternative three-phase choke realisation of [60], [61], with two coaxially placed toroidal cores, can reduce the DM magnetic fringing field, at the expense of added complexity. In summary, the DM fringing field is a significant drawback of the d-FSF and is especially critical for power dense systems where the thee-phase choke must be tightly packed in the inverter PCB assembly. For this reason, a c-FSF, which retains the DM flux inside the employed ELP cores, is a better option.

Finally, the effect of the load grounding technique on the input-side EMI noise profile is examined [19]. Instead of grounding the load only through the shielded cable, an alternative option, where the load is directly grounded (cf., Fig. 16 dashed yellow line applies) is investigated. The EMI measurement results corresponding to the different output filter variants are shown in Fig. 18, for a $10 \mathrm{~m}$ cable. It is evident that directly grounding the load increases the EMI emissions at $350 \mathrm{kHz}$, for all output filter options. By directly grounding the load, output-side parasitic CM currents can directly flow to PE (via the PE connection and not only through parasitic capacitances), instead of returning to the inverter DC link via the cable shield. As highlighted in Fig. 19 these parasitic CM currents form a return path at the input-side and partially flow through the LISN. As a result, additional CM EMI emissions are measured at the input side. The end user of the drive system should be conscious that directly grounding the motor increases the EMI noise profile at the input-side, espically in the case of long motor cables. Ideally, the inverter should be integrated in the same housing as the motor [62], [63]. Thereby, the interconnecting cable is eliminated, resulting in an even better EMI performance for the drive system. 


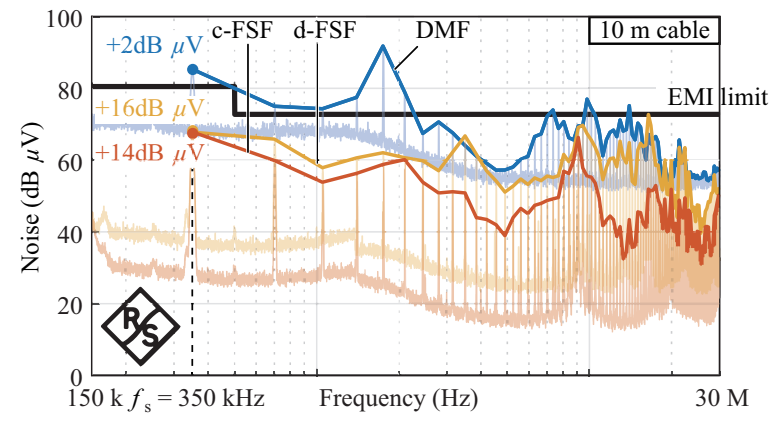

Fig. 18. Conducted EMI noise measurement results at the DC input-side for a $10 \mathrm{~m}$ shielded cable. The measurements of Fig. 17(b) are repeated, but the load is directly grounded. The comparative increase in the EMI noise at $350 \mathrm{kHz}$ is highlighted in the figure.

\section{Conclusions}

High-speed motors are gaining ground compared to conventional low-speed counterparts, thanks to their low volume/weight. Simultaneously, WBG semiconductor devices enable efficient and compact inverter solutions. These recent developments in motor and semiconductor technology allow for significantly better motor drive performance, but pose electromagnetic interference (EMI) concerns. Electromagnetic compatibility (EMC) in high-speed motor drives, supplied by an isolated DC source, is analysed in this paper (cf., Fig. 1). A filter that complies with conducted EMI regulations is typically required at the inverter DC input-side, in order to protect the nearby equipment from EMI noise. There is however no clear mandate requiring from inverters to comply with conducted EMI regulations at the AC output-side, where only the motor is placed. The optimal input/output filter solutions, for a $1 \mathrm{~kW}$ inverter prototype (cf., Fig. 7), driving a 280 krpm electric compressor (cf., Fig. 13(b)), are explored in this paper.

A full sine-wave output filter (FSF) is proposed, which features differential-mode and common-mode (DM/CM) attenuation. A FSF presents three key advantages:

(i) Sinusoidal motor currents. High-speed motors are sensitive to poor stator current quality, which induces high rotor losses. A FSF output filter guarantees sinusoidal motor currents, thanks to its DM attenuation.

(ii) High motor reliability. The fast switching transitions of the latest WBG semiconductor devices generate high $\mathrm{CM} \mathrm{d} u / \mathrm{d} t>$ $30 \mathrm{kV} / \mu \mathrm{s}$, which can damage the motor bearing/insulation. A FSF features CM attenuation, which mitigates high $\mathrm{d} u / \mathrm{d} t$ and protects the motor. The experimental results of Fig. 15 verify the good motor voltage quality, when a FSF is installed.

(iii) Low input-side CM EMI emissions. Since the inverter housing, the motor housing and the interconnecting shielded cable are all grounded, CM emissions generated at the inverter output-side are directly mapped to the inverter input-side (i.e., input-to-output $\mathrm{CM}$ noise mutual influence). This problem is amplified in the case of WBG inverters, where high switching frequencies are employed. A FSF uses capacitors which are connected to the DC link. Thereby, CM emissions can return through these capacitors to the DC link and the semiconductor devices, which created the $\mathrm{CM}$ emissions in the first place.
A FSF reduces CM emissions at the inverter output, hence simultaneously mitigates the input-side $\mathrm{CM}$ emissions. The experimental results of Fig. 17 reveal a significant reduction of the CM EMI emissions at the input-side, when a FSF is installed at the output-side.

Two implementation variants of a FSF are comparatively evaluated, in terms of volume losses and EMI performance:

(i) c-FSF of Fig. 3. This filter variant employs three individual inductors (ELP core type), each corresponding to a phase-leg.

(ii) d-FSF of Fig. 4. This filter variant utilizes a single three-phase toroidal CM choke. The stray inductance of the phase windings is used as DM inductance. For the application at hand, the d-FSF benefits from a lower volume $11.1 \mathrm{~cm}^{3}$ compared to the c-FSF $12.7 \mathrm{~cm}^{3}$ but generates $5 \mathrm{~W}$ of additional losses. Subsequent EMI measurements (cf., Figs. 15 and 17) reveal that the c-FSF exhibits significantly better EMI performance compared to the d-FSF. The main drawback of a d-FSF is the DM fringing magnetic field, which is caused by the leakage inductance of the three-phase choke. This fringing field results in an unwanted magnetic coupling in the vicinity of the choke, which in return causes high overall EMI emissions. In contrast, the c-FSF retains the magnetic flux inside the employed ELP cores and hence is a better solution.

\section{APPENDIX \\ Output Filter Design for High-Speed Drives}

The output filter passive components are subject to strict design constrains when used in high-speed drive systems. The design constrains are derived for the c-FSF of Fig. 3, but can be easily extended for the d-FSF of Fig. 4. Based on (35), the DM resonant frequency of the c-FSF $f_{\mathrm{r}, \mathrm{DM}}$ should be

$$
\underset{f_{\mathrm{r}, \mathrm{DM}, \text { min }}}{f_{\mathrm{m}} a_{\mathrm{f}}} \leqslant f_{\mathrm{r}, \mathrm{DM}}=\frac{1}{2 \pi \sqrt{L_{\mathrm{m}} C_{\mathrm{m}}}} \leqslant \underbrace{a_{\mathrm{f}}}_{f_{\mathrm{r}, \mathrm{DM}, \text { max }}}
$$

A resonant frequency that adheres to the above constraints lies within the design space illustrated in Fig. 20(a). For low switching frequencies $f_{\mathrm{s}} \leqslant a_{\mathrm{f}}^{2} f_{\mathrm{m}}$ the inequality $f_{\mathrm{r}, \mathrm{DM}, \max }<$ $f_{\mathrm{r}, \mathrm{DM}, \mathrm{min}}$ holds, therefore there is no feasible filter design. As the switching frequency increases and exceeds the value $f_{\mathrm{s}} \geqslant a_{\mathrm{f}}^{2}$ $f_{\mathrm{m}}$, the inequality $f_{\mathrm{r}, \mathrm{DM}, \max } \geqslant f_{\mathrm{r}, \mathrm{DM} \text {,min }}$ holds, hence feasible filter designs exist. For the current analysis an output filter with minimum volume is desired, therefore the highest possible DM resonant frequency within the available range (47) is selected, i.e., $f_{\mathrm{r}, \mathrm{DM}}=f_{\mathrm{s}} / a_{\mathrm{f}}$.

The selection of the DM resonant frequency $f_{\mathrm{r}, \mathrm{DM}}$, does not explicitly define the filter inductor/capacitor values. The inductor value $L_{\mathrm{m}}$ and the capacitor value $C_{\mathrm{m}}$ are selected based on reactive power considerations. For a transmitted power per phase $P=\hat{U}_{\mathrm{m}} \hat{I}_{\mathrm{m}} / 2$ the reactive power consumption of the filter inductor $L_{\mathrm{m}}$ is

$$
Q_{\mathrm{L}}=\frac{\hat{I}_{\mathrm{m}}^{2} \omega_{\mathrm{m}} L_{\mathrm{m}}}{2}, a_{\mathrm{L}}=\frac{Q_{\mathrm{L}}}{P}=\frac{j \omega_{\mathrm{m}} L_{\mathrm{m}} \hat{I}_{\mathrm{m}}}{\hat{U}_{\mathrm{m}}},
$$




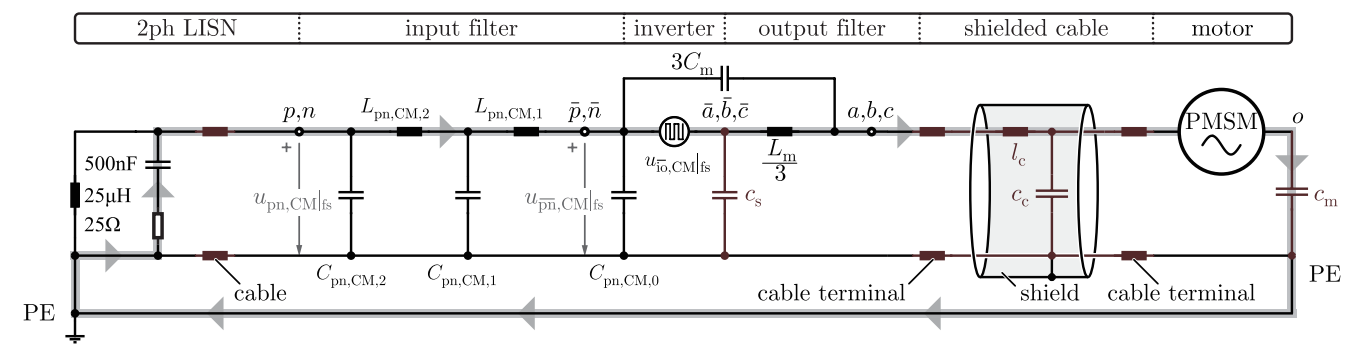

Fig. 19. Effect of direct motor grounding on the input-side conducted EMI emissions. Output-side parasitic CM currents can directly flow to PE (instead of returning to the inverter DC link via the cable shield), and form a return path at the input-side. These parasitic currents partially flow through the LISN (grey path), thus increase the input-side conducted emissions. A two-stage input filter and a c-FSF are assumed.

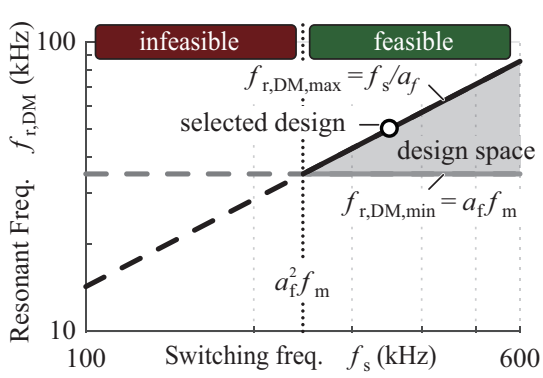

(a)

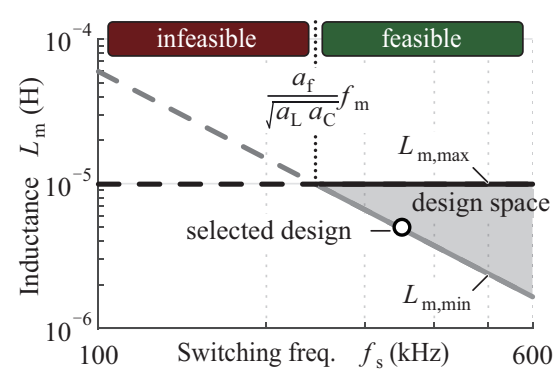

(b)

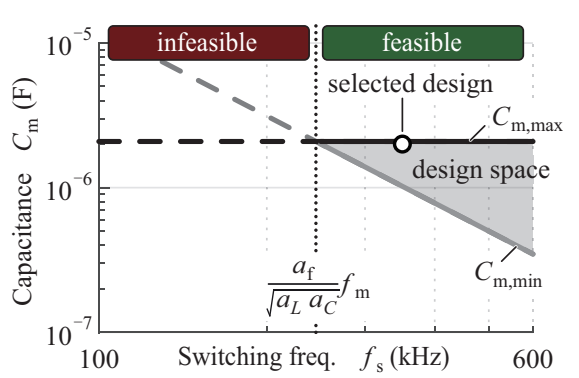

(c)

Fig. 20. Output filter design constraints for $a_{\mathrm{f}}=7$. (a) DM resonant frequency $f_{\mathrm{r}, \mathrm{DM}}$ design constrains, (b) inductor $L_{\mathrm{m}}$ and (c) capacitor $C_{\mathrm{m}}$ design constraints. The selected benchmark design of Table II, which employs a switching frequency of $f_{\mathrm{s}}=350 \mathrm{kHz}$, is highlighted.

while the reactive power consumption of the filter capacitor $C_{\mathrm{m}}$ is

$$
Q_{\mathrm{C}}=\frac{\hat{U}_{\mathrm{m}}^{2} \omega_{\mathrm{m}} \mathrm{C}_{\mathrm{m}}}{2}, a_{\mathrm{C}}=\frac{Q_{\mathrm{C}}}{P}=\frac{j \omega_{\mathrm{m}} C_{\mathrm{m}} \hat{U}_{\mathrm{m}}}{\hat{I}_{\mathrm{m}}} .
$$

The reactive power consumptions $Q_{\mathrm{L}}$ and $Q_{\mathrm{C}}$ both scale linearly with the fundamental frequency $f_{\mathrm{m}}$. Although the output filter reactive power is negligible for a fundamental frequency of $f_{\mathrm{m}}$ $=50 \mathrm{~Hz}$, it becomes significant for high-speed drive systems with fundamental frequencies up to $f_{\mathrm{m}}=5 \mathrm{kHz}$. The reactive power $Q_{\mathrm{L}}$ or $Q_{\mathrm{C}}$ should not exceed $30 \%$ of the active power $P$, i.e., $\left\{a_{\mathrm{L}}, a_{\mathrm{C}}\right\}<0.3$. This limitation of the reactive power directly provides the maximum allowed inductance $L_{\mathrm{m}, \max }$ and capacitance $C_{\mathrm{m}, \max }$ values, given in (50) and (51), respectively. Furthermore, based on the selected DM resonant frequency $f_{\mathrm{r}, \mathrm{DM}}=f_{\mathrm{s}} / a_{\mathrm{f}}$ the minimum allowable inductance $L_{\mathrm{m}, \min }$ and capacitance $C_{\mathrm{m}, \min }$ are also calculated

$$
\begin{aligned}
& \frac{1}{C_{\mathrm{m}, \text { max }} \omega_{\mathrm{r}, \mathrm{DM}}^{2}}=\frac{a_{\mathrm{f}}^{2} \omega_{\mathrm{m}} R}{\frac{\omega_{\mathrm{s}}^{2} a_{\mathrm{C}}}{L_{\mathrm{m}, \min }}} \leqslant L_{\mathrm{m}} \leqslant \frac{a_{\mathrm{L}} R}{\omega_{\mathrm{m}, \max }}, \\
& \frac{1}{L_{\mathrm{m}, \text { max }} \omega_{\mathrm{r}, \mathrm{DM}}^{2}}=\frac{a_{\mathrm{f}}^{2} \omega_{\mathrm{m}}}{\underbrace{\omega_{\mathrm{L}}^{2} a_{\mathrm{L}}}_{c_{\mathrm{m}, \mathrm{min}}}} \leqslant C_{\mathrm{m}} \leqslant \frac{a_{\mathrm{C}}}{\frac{\omega_{\mathrm{m}} R}{C_{\mathrm{m}, \text { max }}}},
\end{aligned}
$$

where $R=\hat{U}_{\mathrm{m}} / \hat{I}_{\mathrm{m}}$ is the equivalent load resistance per phase. The feasible $L_{\mathrm{m}}$ and $C_{\mathrm{m}}$ design space is illustrated in Fig. 20(b) and (c), respectively. There, for low switching frequencies $f_{\mathrm{s}}<$ $a_{\mathrm{f}} / \sqrt{a_{\mathrm{C}} a_{\mathrm{L}}} f_{\mathrm{m}}$ the inequality $L_{\mathrm{m}, \text { max }}<L_{\mathrm{m} \text {,min }}$ holds, therefore there is no feasible inductor design. As the switching frequency increases and exceeds the value $f_{\mathrm{s}} \geqslant a_{\mathrm{f}} / \sqrt{a_{\mathrm{C}} a_{\mathrm{L}}} f_{\mathrm{m}}$, the inequality $L_{\mathrm{m}, \max } \geqslant L_{\mathrm{m}, \min }$ holds, hence, feasible inductor designs exist. Similarly, only switching frequencies $f_{\mathrm{s}} \geqslant a_{\mathrm{f}} / \sqrt{a_{\mathrm{C}} a_{\mathrm{L}}} f_{\mathrm{m}}$ allow for a feasible capacitor $C_{\mathrm{m}}$ design (cf., Fig. 20(c)).

In general, the resonant frequency $f_{\mathrm{r}, \mathrm{DM}}$ constrains require a switching frequency $f_{\mathrm{s}} \geqslant a_{\mathrm{f}}^{2} f_{\mathrm{m}}$ (cf., Fig. 20(a)), while the inductor $L_{\mathrm{m}}$ constrains and/or the capacitor $C_{\mathrm{m}}$ constrains require a switching frequency $f_{\mathrm{s}} \geqslant a_{\mathrm{f}} / \sqrt{a_{\mathrm{C}} a_{\mathrm{L}}} f_{\mathrm{m}}$. Since both switching frequency $f_{\mathrm{s}}$ inequalities must be satisfied it is reasonable to simplify as

$$
\frac{a_{\mathrm{f}}}{\sqrt{a_{\mathrm{C}} a_{\mathrm{L}}}} f_{\mathrm{m}}=a_{\mathrm{f}}^{2} f_{\mathrm{m}} \rightarrow a_{\mathrm{C}}=a_{\mathrm{L}}=\frac{1}{a_{\mathrm{f}}} .
$$

The selection of the parameter $a_{\mathrm{f}}$ is crucial. Excessively high $a_{\mathrm{f}}$ values could over-constrain the filter design. Empirically, the parameter value $a_{\mathrm{f}}=7$ is suggested.

In summary, a c-FSF is designed as follows:

(i) A switching frequency $f_{\mathrm{s}} \geqslant a_{\mathrm{f}}^{2} f_{\mathrm{m}}=a_{\mathrm{f}} / \sqrt{a_{\mathrm{C}} a_{\mathrm{L}}} f_{\mathrm{m}}$ is selected.

(ii) The maximum possible DM resonant frequency $f_{\mathrm{r}, \mathrm{DM}}$ $=f_{\mathrm{s}} / a_{\mathrm{f}}$ is selected, in order to achieve minimum output filter volume.

(iii) The minimum possible inductance value $L_{\mathrm{m}}=L_{\mathrm{m}, \min }$ of (50), and the maximum capacitance value $C_{\mathrm{m}}=C_{\mathrm{m}, \max }$ of (51) are selected. These passive component values yields the smallest output filter volume, since inductors are typically bulkier compared to capacitors. 


\section{ACKNOWLEDGMENT}

The authors gratefully acknowledge the financial support by the Swiss Innovation Agency (Innosuisse) and the technical contribution of Celeroton $\mathrm{AG}$.

\section{REFERENCES}

[1] C. Zwyssig, J. W. Kolar, and S. D. Round, "Megaspeed drive systems: pushing beyond 1 million r/min," in IEEE/ASME Transactions on Mechatronics, vol. 14, no. 5, pp. 564-574, Oct. 2009.

[2] M. A. Rahman, A. Chiba, and T. Fukao, "Super high speed electrical machines -summary," in Proceedings of IEEE Power Engineering Society General Meeting, Jun. 2004, pp. 1272-1275.

[3] IEC 61800-3 Adjustable Speed Electrical Power Drive Systems - EMC Requirements and Specific Test Methods, IEC Standard, 2019.

[4] S. Li, Y. Li, W. Choi, and B. Sarlioglu, "High-speed electric machines: challenges and design considerations," in IEEE Transactions on Transportation Electrification, vol. 2, no. 1, pp. 2-13, Mar. 2016.

[5] A. Looser, T. Baumgartner, C. Zwyssig, and J. W. Kolar, "Analysis and measurement of $3 \mathrm{~d}$ torque and forces for permanent magnet motors with slotless windings," in Proceedings of IEEE Energy Conversion Congress and Exposition (ECCE USA), Sep. 2010, pp. 3792-3797.

[6] K. Shirabe, M. Swamy, J. Kang, M. Hisatsune, Y. Wu, D. Kebort, and J. Honea, "Advantages of high frequency PWM in AC motor drive applications," in Proceedings of IEEE Energy Conversion Congress and Exposition (ECCE USA), 2012, pp. 2977-2984.

[7] A. Von Jouanne and P. N. Enjeti, "Design considerations for an inverter output filter to mitigate the effects of long motor leads in asd applications," in IEEE Transactions on Industry Applications, vol. 33, no. 5, pp. 1138 1145, Sep. 1997.

[8] R. J. Kerkman, D. Leggate, and G. L. Skibinski, "Interaction of drive modulation and cable parameters on AC motor transients," in IEEE Transactions on Industry Applications, vol. 33, no. 3, pp. 722-731, MayJun. 1997.

[9] D. Leggate, J. Pankau, D. W. Schlegel, R. J. Kerkman, and G. L. Skibinski, "Reflected waves and their associated [current in IGBT VSIs]" in IEEE Transactions on Industry Applications, vol. 35, no. 6, pp. 1383-1392, Nov. -Dec. 1999.

[10] D. Han, S. Li, Y. Wu, W. Choi, and B. Sarlioglu, "Comparative analysis on conducted CM EMI emission of motor drives: WBG versus Si devices," in IEEE Transactions on Industrial Electronics, vol. 64, no. 10, pp. 83538363, Oct. 2017.

[11] E. A. Jones, F. Wang, D. Costinett, Z. Zhang, B. Guo, B. Liu, and R. Ren, "Characterization of an enhancement-mode 650-V GaN HFET," in Proceedings of IEEE Energy Conversion Congress and Exposition (ECCE), Montreal, QC, Canada, Sep. 2015, pp. 400-407.

[12] D. Bortis, O. Knecht, D. Neumayr, and J. W. Kolar, "Comprehensive evaluation of GaN GIT in low-and high-frequency bridge leg applications," in Proceedings of 2016 IEEE 8th International Power Electronics and Motion Control Conference (IPEMC-ECCE Asia), Hefei, China, May 2016, pp. 21-30.

[13] J. M. Erdman, R. J. Kerkman, D. W. Schlegel, and G. L. Skibinski, "Effect of PWM inverters on AC motor bearing currents and shaft voltages," in IEEE Transactions on Industry Applications, vol. 32, no. 2, pp. 250-259, Mar. -Apr. 1996.

[14] D. Busse, J. Erdman, R. J. Kerkman, D. Schlegel, and G. Skibinski, "Bearing currents and their relationship to PWM drives," in IEEE Transactions on Power Electronics, vol. 12, no. 2, pp. 243-252, Mar. 1997.

[15] D. Busse, J. Erdman, R. Kerkman, D. Schlegel, and G. Skibinski, "Characteristics of shaft voltage and bearing currents," in IEEE Industry Applications Magazine, vol. 3, no. 6, pp. 21-32, Nov. -Dec. 1997.

[16] D. Busse, J. Erdman, R. J. Kerkman, D. Schlegel, and G. Skibinski, “System electrical parameters and their effects on bearing currents," in IEEE Transactions on Industry Applications, vol. 33, no. 2, pp. 577-584, Mar. -Apr. 1997.

[17] M. Kaufhold, H. Aninger, M. Berth, J. Speck, and M. Eberhardt, "Electrical stress and failure mechanism of the winding insulation in pwm-inverterfed low-voltage induction motors," in IEEE Transactions on Industrial Electronics, vol. 47, no. 2, pp. 396-402, Apr. 2000.

[18] S. Schroth, D. Bortis, and J. W. Kolar, "Impact of stator grounding in low power single-phase EC-motors," in Proceedings of 2014 IEEE Applied Power Electronics Conference and Exposition (APEC), Fort Worth, TX, USA, Mar. 2014, pp. 783-790.

[19] H. Akagi and T. Shimizu, "Attenuation of conducted EMI emissions from an inverter-driven motor," in IEEE Transactions on Power Electronics, vol. 23, no. 1, pp. 282-290, Jan. 2008.

[20] X. Zhang, D. Boroyevich, P. Mattavelli, J. Xue, and F. Wang, "EMI filter design and optimization for both $\mathrm{AC}$ and DC side in a DC-fed motor drive system," in Proceedings of 2013 28th Annual IEEE Applied Power Electronics Conference and Exposition (APEC), Long Beach, CA, USA, 2013, pp. 597-603.

[21] M. M. Swamy, J. Kang, and K. Shirabe, "Power loss, system efficiency, and leakage current comparison between Si IGBT VFD and SiC FET VFD with various filtering options," in IEEE Transactions on Industry Applications, vol. 51, no. 5, pp. 3858-3866, Sep. -Oct. 2015.

[22] G. Skibinski, J. Pankau, R. Sladky, and J. Campbell, "Generation, control and regulation of EMI from AC drives," in Proceedings of 1997 IEEE Industry Applications Conference Thirty -2nd IAS Annual Meeting, New Orleans, LA, USA, vol. 2, Oct. 1997, pp. 1571-1583.

[23] G. L. Skibinski, R. J. Kerkman, and D. Schlegel, "EMI emissions of modern PWM AC drives," in IEEE Industry Applications Magazine, vol. 5, no. 6, pp. 47-80, 1999.

[24] D. Rendusara and P. Enjeti, "New inverter output filter configuration reduces common mode and differential mode dv/dt at the motor terminals in PWM drive systems," in Proceedings of 1997 28th Annual IEEE Power Electronics Specialists Conference (PESC), St. Louis, MO, USA. Jun. 1997, pp. 1269-1275.

[25] D. A. Rendusara and P. N. Enjeti, "An improved inverter output filter configuration reduces common and differential modes $\mathrm{d} v / \mathrm{d} t$ at the motor terminals in PWM drive systems," in IEEE Transactions on Power Electronics, vol. 13, no. 6, pp. 1135-1143, Nov. 1998.

[26] C. Marxgut, J. Biela, and J. W. Kolar, "Interleaved Triangular Current Mode (TCM) resonant transition, single phase PFC rectifier with high efficiency and high power density," in Proceedings of the 2010 International Power Electronics Conference - ECCE ASIA, Sapporo, Japan, 2010, pp. 1725-1732.

[27] C. Marxgut, F. Krismer, D. Bortis, and J. W. Kolar, "Ultraflat interleaved triangular current mode (TCM) single-phase PFC rectifier," in IEEE Transactions on Power Electronics, vol. 29, no. 2, pp. 873-882, Feb. 2014.

[28] M. Kaufmann, A. Tüysüz, and J. W. Kolar, "New optimum modulation of three-phase ZVS triangular current mode GaN inverter ensuring limited switching frequency variation," in Proceedings of 8th IET International Conference on Power Electronics, Machines and Drives (PEMD 2016), Glasgow, UK, 2016, pp. 1-6.

[29] R. M. Tallam, G. L. Skibinski, T. A. Shudarek, and R. A. Lukaszewski, "Integrated differential-mode and common-mode filter to mitigate the effects of long motor leads on AC drives," in IEEE Transactions on Industry Applications, vol. 47, no. 5, pp. 2075-2083, Sep -Oct. 2011.

[30] F. Maislinger, H. Ertl, G. Stojcic, C. Lagler, and F. Holzner, "Design of a $100 \mathrm{khz}$ wide bandgap inverter for motor applications with active damped sine wave filter," in The Journal of Engineering, vol. 2019, no. 17, pp. 3766-3771, 2019.

[31] Y. Murai, T. Kubota, and Y. Kawase, "Leakage current reduction for a high-frequency carrier inverter feeding an induction motor," in IEEE Transactions on Industry Applications, vol. 28, no. 4, pp. 858-863, Jul. 1992.

[32] M. M. Swamy, K. Yamada, and T. Kume, "Common mode current 
attenuation techniques for use with PWM drives," in IEEE Transactions on Power Electronics, vol. 16, no. 2, pp. 248-255, Mar. 2001.

[33] T. A. Lipo and E. Zhong, "Inverter-fed motor drive with EMI supression," U.S. Patent 5661 390, 1995.

[34] X. Chen, D. Xu, F. Liu, and J. Zhang, "A novel inverter-output passive filter for reducing both differential-and common-mode $\mathrm{d} v / \mathrm{d} t$ at the motor terminals in PWM drive systems," in IEEE Transactions on Industrial Electronics, vol. 54, no. 1, pp. 419-426, Feb. 2007.

[35] A. L. Julian, G. Oriti, and T. A. Lipo, "Elimination of common-mode voltage in three-phase sinusoidal power converters," in IEEE Transactions on Power Electronics, vol. 14, no. 5, pp. 982-989, Sep. 1999.

[36] K. Euerle, K. Iyer, E. Severson, R. Baranwal, S. Tewari, and N. Mohan, “A compact active filter to eliminate common-mode voltage in a SiC-based motor drive," in Proceedings of 2016 IEEE Energy Conversion Congress and Exposition (ECCE), Milwaukee, WI, USA, 2016, pp. 1-8.

[37] A. M. Hava, R. J. Kerkman, and T. A. Lipo, "Simple analytical and graphical methods for carrier-based PWM-VSI drives," in IEEE Transactions on Power Electronics, vol. 14, no. 1, pp. 49-61, Jan. 1999.

[38] K. Zhou and D. Wang, "Relationship between space-vector modulation and three-phase carrier-based PWM: A comprehensive analysis," in IEEE Transactions on Industrial Electronics, vol. 49, no. 1, pp. 186-196, Feb. 2002.

[39] S. Ogasawara and H. Akagi, "Modeling and damping of high-frequency leakage currents in PWM inverter-fed AC motor drive systems," in IEEE Transactions on Industry Applications, vol. 32, no. 5, pp. 1105-1114, 1996.

[40] Haoyi Ye, Zhihui Yang, Jingya Dai, Chao Yan, Xiaoni Xin, and Jianping Ying, "Common mode noise modeling and analysis of dual boost PFC circuit," in Proceedings of INTELEC 2004. 26th Annual International Telecommunications Energy Conference, Chicago, IL, USA, 2004, pp. 575-582.

[41] J. W. Kolar and S. D. Round, "Analytical calculation of the RMS current stress on the DC-link capacitor of voltage-PWM converter systems," in IEEE Electric Power Applications, vol. 153, no. 4, pp. 535-543, Jul. 2006.

[42] M. J. Nave, "On modeling the common mode inductor," in Proceedings of IEEE 1991 International Symposium on Electromagnetic Compatibility, Cherry Hill, NJ, USA, 1991, pp. 452-457.

[43] D. Han, C. T. Morris, W. Lee, and B. Sarlioglu, "Three-phase common mode inductor design and size minimization," in Proceedings of 2016 IEEE Transportation Electrification Conference and Expo (ITEC), Dearborn, MI, USA, 2016, pp. 1-8.

[44] J. W. Kolar, F. Krismer, Y. Lobsiger, J. Muhlethaler, T. Nussbaumer, and J. Minibock, "Extreme efficiency power electronics," in Proceedings of 2012 7 th International Conference on Integrated Power Electronics Systems (CIPS), Nuremberg, Germany, 2012, pp. 1-22.

[45] D. Bortis, D. Neumayr, and J. W. Kolar, " $\eta \rho$-Pareto optimization and comparative evaluation of inverter concepts considered for the GOOGLE Little Box Challenge," in Proceedings of 2016 IEEE 17th Workshop on Control and Modeling for Power Electronics (COMPEL), Trondheim, Norway, 2016, pp. 1-5.

[46] R. M. Burkart, H. Uemura, and J. W. Kolar, "Optimal inductor design for 3-phase voltage-source PWM converters considering different magnetic materials and a wide switching frequency range," in Proceedings of 2014 International Power Electronics Conference (IPEC-Hiroshima 2014 ECCE ASIA), Hiroshima, Japan, 2014, pp. 891-898.

[47] P. Papamanolis, F. Krismer, and J. W. Kolar, "Minimum loss operation of high-frequency inductors," in Proceedings of 2018 IEEE Applied Power Electronics Conference and Exposition (APEC), San Antonio, TX, USA, 2018, pp. 1756-176.

[48] J. A. Anderson, E. J. Hanak, L. Schrittwieser, M. Guacci, J. W. Kolar, and G. Deboy, "All-silicon 99.35\% efficient three-phase seven-level hybrid neutral point clamped/flying capacitor inverter," in CPSS Transactions on Power Electronics and Applications, vol. 4, no. 1, pp. 50-61, Mar. 2019.

[49] C. Gammeter, F. Krismer, and J. W. Kolar, "Weight optimization of a cooling system composed of fan and extruded-fin heat sink," in IEEE Transactions on Industry Applications, vol. 51, no. 1, pp. 509-520, Jan.
2015 .

[50] K. Raggl, T. Nussbaumer, and J. W. Kolar, "Guideline for a simplified differential-mode EMI filter design," in IEEE Transactions on Industrial Electronics, vol. 57, no. 3, pp. 1031-1040, Mar. 2010.

[51] Nanocrystalline Vitroperm EMC Components,Vacuumschmelze (VAC) GmbH Co., Hanau, Germany, 2017.

[52] Shuo Wang, F. C. Lee, D. Y. Chen, and W. G. Odendaal, "Effects of parasitic parameters on EMI filter performance," in IEEE Transactions on Power Electronics, vol. 19, no. 3, pp. 869-877, 2004.

[53] D. Han, C. T. Morris, W. Lee, and B. Sarlioglu, "Comparison between output CM chokes for SiC drive operating at 20- and 200-khz switching frequencies," in IEEE Transactions on Industry Applications, vol. 53, no. 3, pp. 2178-2188, May 2017.

[54] M. L. Heldwein, L. Dalessandro, and J. W. Kolar, "The three-phase common-mode inductor: Modeling and design issues," in IEEE Transactions on Industrial Electronics, vol. 58, no. 8, pp. 3264-3274, Aug. 2011.

[55] S. Ogasawara, H. Ayano, and H. Akagi, "Measurement and reduction of EMI radiated by a PWM inverter-fed AC motor drive system," in IEEE Transactions on Industry Applications, vol. 33, no. 4, pp. 1019-1026, Jul.Aug. 1997.

[56] S. Bell, T. J. Cookson, S. A. Cope, R. A. Epperly, A. Fischer, D. W. Schlegel, and G. L. Skibinski, "Experience with variable-frequency drives and motor bearing reliability," in IEEE Transactions on Industry Applications, vol. 37, no. 5, pp. 1438-1446, 2001.

[57] Celeroton. (2017) Radial turbo compressor CT-17-1000. [Online]. Available: https://www.celeroton.com/fileadmin/user upload/produkte/ kompressor/datasheets/Datasheet-CT-17-1000.pdf

[58] Z. Vrankovic, G. L. Skibinski, and C. Winterhalter, "Novel double clamp methodology to reduce shielded cable radiated emissions initiated by electronic device switching," in IEEE Transactions on Industry Applications, vol. 53, no. 1, pp. 327-339, Jan. 2017.

[59] R. Wang, H. F. Blanchette, M. Mu, D. Boroyevich, and P. Mattavelli, "Influence of high-frequency near-field coupling between magnetic components on EMI filter design," in IEEE Transactions on Power Electronics, vol. 28, no. 10, pp. 4568-4579, Oct. 2013.

[60] R. Lai, Y. Maillet, F. Wang, S. Wang, R. Burgos, and D. Boroyevich, “An integrated EMI choke for differential-mode and common-mode noise suppression," in IEEE Transactions on Power Electronics, vol. 25, no. 3, pp. 539-544, 2010.

[61] Y. Maillet, R. Lai, S. Wang, F. Wang, R. Burgos, and D. Boroyevich, "High density EMI filter design for DC fed motor drives," in IEEE Transactions on Power Electronics, vol. 25, no. 5, pp. 1163-1172, Mar. 2010.

[62] T. M. Jahns and H. Dai, "The past, present, and future of power electronics integration technology in motor drives," in CPSS Transactions on Power Electronics and Applications, vol. 2, no. 3, pp. 197-216, Sep. 2017.

[63] R. A. Torres, H. Dai, W. Lee, T. M. Jahns, and B. Sarlioglu, "Current source inverters for integrated motor drives using wide-bandgap power switches," in Proceedings of IEEE Transportation Electrification Conference and Expo (ITEC), Long Beach, CA, USA 2018, pp. 1002-1008.

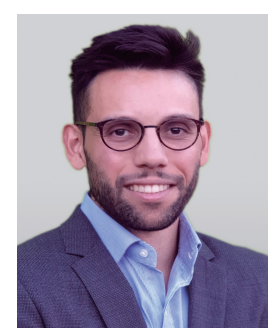

Michael Antivachis received his B.Sc. degree in electrical and computer engineering from the National Technical University of Athens (NTUA). He then received his M.Sc. and Ph.D. degrees from the Swiss Federal Institute of Technology (ETH) Zurich in 2016 and 2020, respectively. Since 2016, he is with the Power Electronic Systems Laboratory (PES) of ETH Zurich as a scientific researcher. His research interests include high-speed motor drive systems, efficient and power dense inverter solutions employing wide-bandgap semiconductor devices, inverter-motor integration, and low EMI emission profile inverters. 


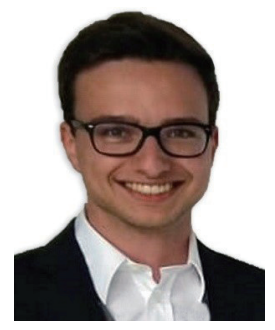

Pascal Samuel Niklaus received his B.Sc. and M.Sc. degrees (with distinction) in electrical engineering from the Swiss Federal Institute of Technology (ETH) Zurich, Switzerland, in 2016 and 2018, respectively. During his studies he did two internships where he developed hardware, firmware and software for custom and off-theshelf test and measurement equipment as well as working on the firmware development for a new microprocessor architecture. In April 2018 he joined the Power Electronic Systems Laboratory (PES) at ETH Zurich as a Ph.D. student focusing on advanced measurement technologies in the field of power electronics as well as ultra-high bandwidth inverter systems.

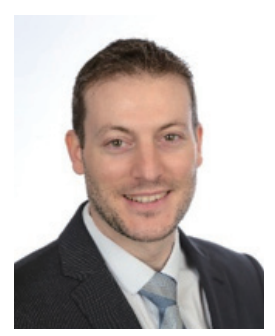

Dominik Bortis received the M.Sc. and Ph.D. degrees in electrical engineering from the Swiss Federal Institute of Technology (ETH) Zurich, Switzerland, in 2005 and 2008, respectively. In May 2005, he joined the Power Electronic Systems Laboratory (PES), ETH Zurich, as a Ph.D. student. From 2008 to 2011, he has been a Postdoctoral Fellow and from 2011 to 2016 a Research Associate with PES, co-supervising Ph.D. students and leading industry research projects. Since January 2016 Dr. Bortis is heading the research group Advanced Mechatronic Systems at PES, which concentrates on ultra-high speed motors, magnetic bearings and bearingless drives, new linear-rotary actuator and machine concepts with integrated power electronics. In this context, multi-objective optimizations concerning weight/volume/efficiency/costs, the analysis of interactions of power electronics and electric machines, and EMI are given special attention. Targeted applications include advanced industry automation and manufacturing, e.g., highly dynamic and precise positioning systems, medical and pharmaceutical systems, e.g., ultra-high purity and blood pumps, and future mobility concepts, including motors and actuators for hybrid and electric vehicles, more electric aircraft and satellites. Dr. Bortis has published more than 90 scientific papers in international journals and conference proceedings. He has filed 32 patents and has received 6 IEEE Conference Prize Paper Awards.

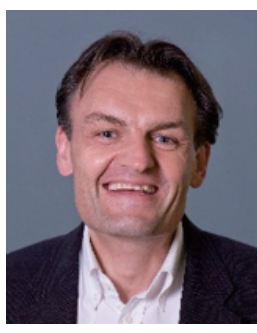

Johann Walter Kolar is a Fellow of the IEEE and received his M.Sc. degree in industrial electronics and control engineering and his Ph.D. degree in electrical engineering (summa cum laude/promotio sub auspiciis praesidentis rei publicae) from the Vienna University of Technology, Austria, in 1997 and 1999, respectively. Since 1984, he has been working as independent researcher and international consultant in close collaboration with the Vienna University of Technology, in the fields of power electronics, industrial electronics and high performance drive systems. He is currently a Full Professor and the Head of the Power Electronic Systems Laboratory at the Swiss Federal Institute of Technology (ETH) Zurich. He has proposed numerous novel PWM converter topologies, modulation and control concepts, multi-objective power electronics design procedures, etc. and has supervised $75+$ Ph.D. students. He has published $900+$ scientific papers in international journals and conference proceedings, 4 book chapters, and has filed $190+$ patents. He has presented $30+$ educational seminars at leading international conferences, has served as IEEE PELS Distinguished Lecturer from 2012 through 2016, and has received 36 IEEE Transactions and Conference Prize Paper Awards, the 2014 IEEE Power Electronics Society R. David Middlebrook Achievement Award, the 2016 IEEE William E. Newell Power Electronics Award, the 2016 IEEE PEMC Council Award, and two ETH Zurich Golden Owl Awards for excellence in teaching. He has initiated and/or is the founder of 4 ETH Spin-off companies. The focus of his current research is on ultra-compact and ultra-efficient $\mathrm{SiC}$ and $\mathrm{GaN}$ converter systems, ANN-based power electronics components and systems design, solidstate transformers, power supplies on chip, as well as ultra-high speed and ultra-light weight drives, bearingless motors, and energy harvesting. 